\title{
Assessment of Tools and Data for System-Level Dynamic Analyses
}

Steven J. Piet

Nick R. Soelberg

June 2011

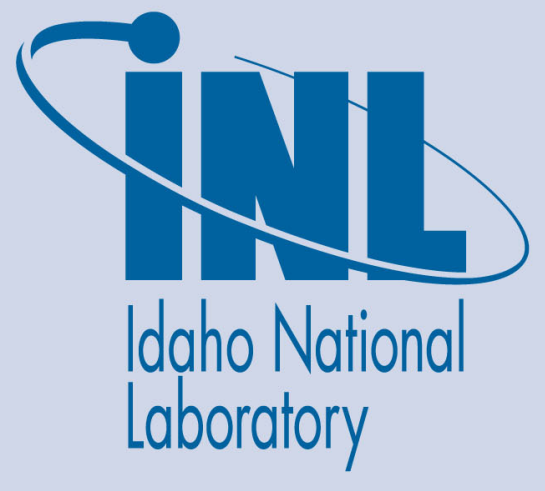

The INL is a U.S. Department of Energy National Laboratory operated by Battelle Energy Alliance 
INL/EXT-11-22588

FCRD-SYSA-2011-000146

\title{
Assessment of Tools and Data for System-Level Dynamic Analyses
}

\author{
Steven J. Piet \\ Nick R. Soelberg \\ June 2011 \\ Idaho National Laboratory \\ Fuel Cycle Research \& Development \\ Idaho Falls, Idaho 83415 \\ http://www.inl.gov \\ Prepared for the \\ U.S. Department of Energy \\ Office of Nuclear Energy \\ Under DOE Idaho Operations Office \\ Contract DE-AC07-05ID14517
}




\section{DISCLAIMER}

This information was prepared as an account of work sponsored by an agency of the U.S. Government. Neither the U.S. Government nor any agency thereof, nor any of their employees, makes any warranty, expressed or implied, or assumes any legal liability or responsibility for the accuracy, completeness, or usefulness, of any information, apparatus, product, or process disclosed, or represents that its use would not infringe privately owned rights. References herein to any specific commercial product, process, or service by trade name, trade mark, manufacturer, or otherwise, does not necessarily constitute or imply its endorsement, recommendation, or favoring by the U.S. Government or any agency thereof. The views and opinions of authors expressed herein do not necessarily state or reflect those of the U.S. Government or any agency thereof. 


\section{SUMMARY}

Dynamic analyses can influence the relative desirability of fuel cycle options. Dynamic analyses show how a fuel cycle might work during transitions from today's partial fuel cycle to something more complete, impact of technology deployments, location of choke points, the key time lags, when benefits can manifest, and how well parts of fuel cycles work together. This report summarizes the readiness of existing Fuel Cycle Technology (FCT) tools and data for conducting dynamic analyses on the range of options.

VISION is the primary dynamic analysis tool. Not only does it model mass flows, as do other dynamic system analysis models, but it allows users to explore various potential constraints. Comparative analyses of fuel cycles must address what constraints exist and how they could impact performance. The most immediate tool need is extending VISION to the thorium/U233 fuel cycle as that is the largest portion of option space beyond current tool coverage. Depending on further clarification of waste management strategies in general and for specific fuel cycle candidates, waste management sub-models in VISION may need enhancement, e.g., more on "co-flows" of non-fuel materials, constraints in waste streams, or automatic classification of waste streams on the basis of user-specified rules. VISION originally had an economic sub-model. The economic calculations were deemed unnecessary in later versions so it was retired. Eventually, the program will need to restore and improve the economics sub-model of VISION to at least the cash flow stage and possibly to incorporating cost constraints and feedbacks.

There are multiple sources of data that dynamic analyses can draw on. In this report, "data" means experimental data, data from more detailed theoretical or empirical calculations on technology performance, and assumptions such as the earliest date a technology can be deployed. Even for once through LWRs, there remain missing data such as how the fuel cycle would be completed with a geologic repository. The most immediate data needs are probably basic reactor physics data for new concepts and data associated with waste management for anything other than current technology. Example 1, we lack a defendable basis for minimum wet storage times for most candidate fuels other than (a) LWR UOX or (b) onsite separation of fast reactor metal fuel, e.g. at EBR-II. Example 2, we know little about waste forms for waste streams arising from fuel fabrication. Where we do have data, often it is of fairly old technologies, hardly appropriate for judging advanced fuel cycles to be deployed decades from now. Beyond waste management, when economics is restored in dynamic analyses tools, we will need estimates of both capital cost and operating and maintenance costs.

The readiness of tools and data is fluid and depends on what purposes are envisioned to drive upcoming analyses and further definition of the waste-related characteristics of fuel cycle candidates. Tools and data sets evolve as needs evolve. Thus, much of the document explains that if the FCT program wants a certain type of analysis, then the tools and data needs are as indicated. For example, functions can be treated as either commodities or facilities. Reactors, separation, fuel fabrication, repository are treated as facility types. Other functions such as uranium mining, conversion, enrichment, and waste packaging and non-repository disposal are treated as commodities and therefore not modeled as extensively. For example, if the FCT program wants to explore the implications of time lags in opening new uranium mines or enrichment plants, then the VISION's uranium sub-models would have to be converted from commodity to facility. In summary, the tools are functional and can answer many fuel cycle questions but some analyses will require that the tools be modified to support those analyses. 


\section{CONTENTS}

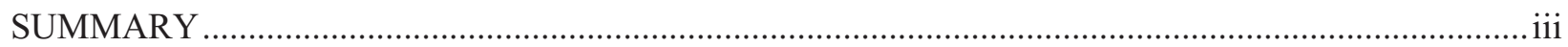

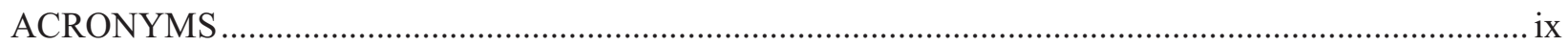

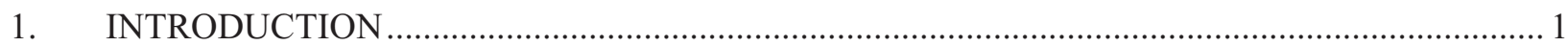

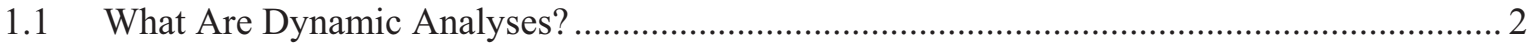

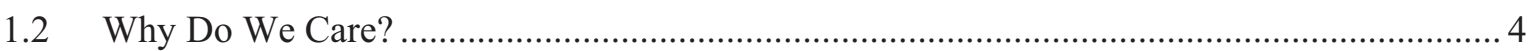

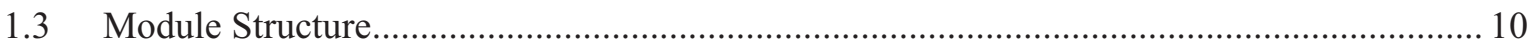

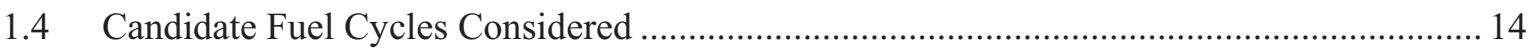

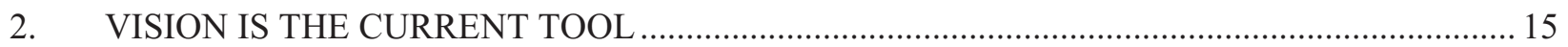

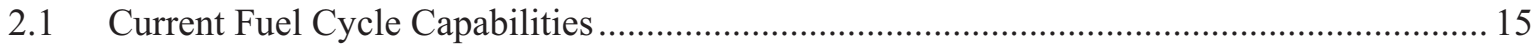

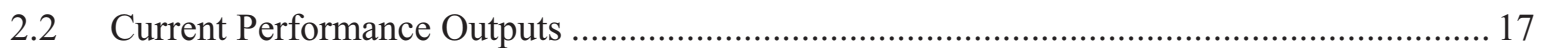

2.3 Missing Category of Fuel Cycles - Thorium/U233 ….................................................... 18

2.4 Likely Need More Waste Management …….................................................................... 19

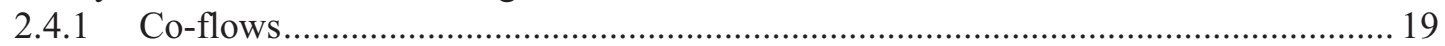

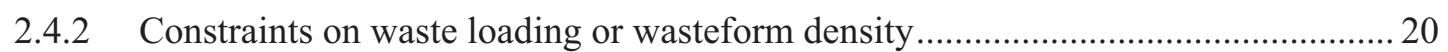

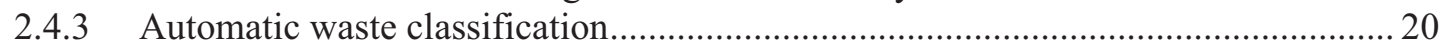

2.5 Likely Need More Grouping and Routing Options..................................................... 21

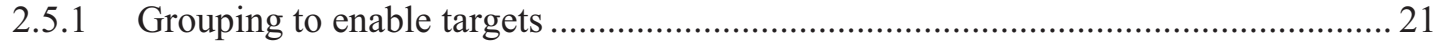

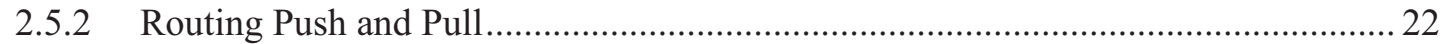

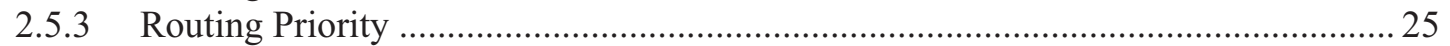

2.6 May Need More Reactor Physics Options .......................................................................... 25

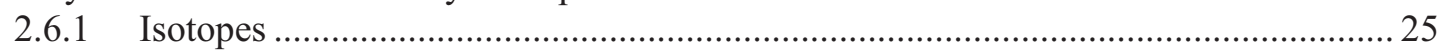

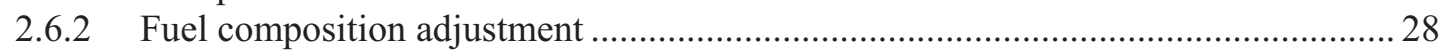

2.6.3 Externally Driven Fuel or Waste Management....................................................... 29

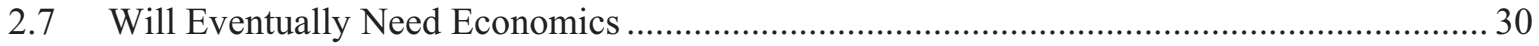

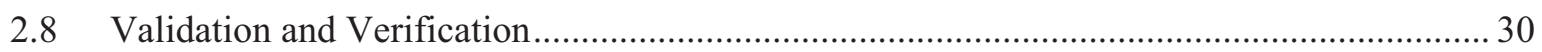

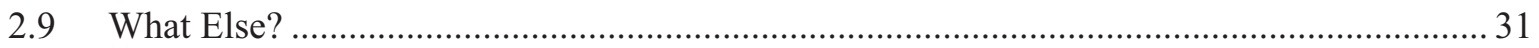

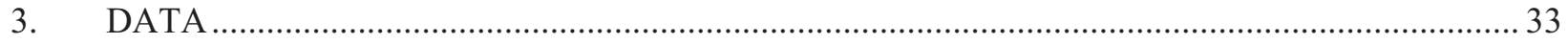

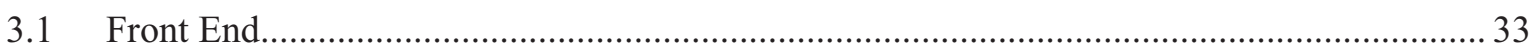

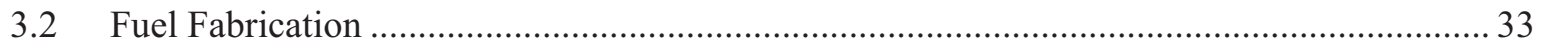

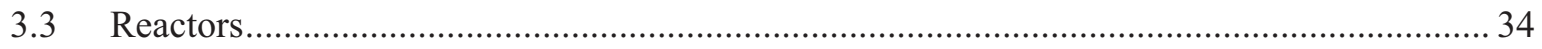

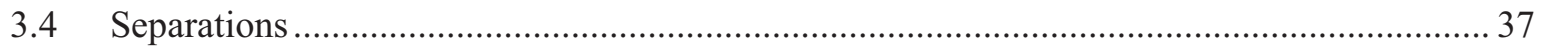

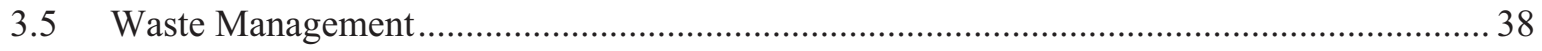

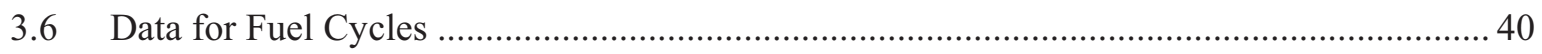

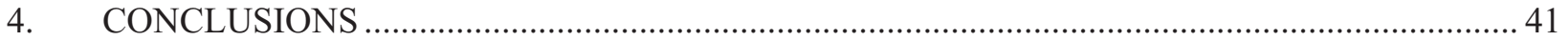

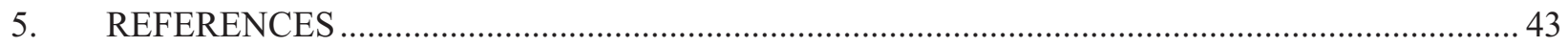




\section{FIGURES}

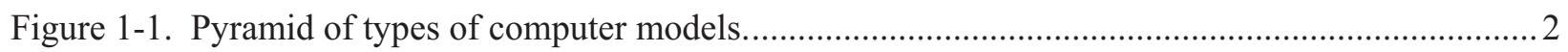

Figure 1-2. Uranium utilization at static equilibrium as function of TRU conversion ratio.......................5

Figure 1-3. Sustainable fast breeder reactor growth rate as function of total turnaround time (in-

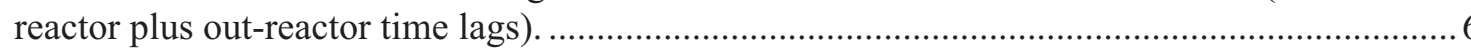

Figure 1-4. Preliminary estimates of percent electricity from fast reactors with $1.75 \% / \mathrm{yr}$ growth

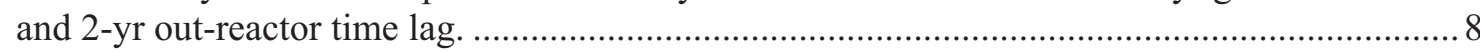

Figure 1-5. Preliminary estimates of percent electricity from fast reactors with $1.75 \% / \mathrm{yr}$ growth

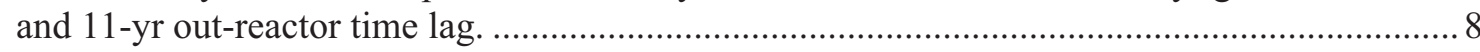

Figure 1-6. Preliminary estimates of uranium consumption with $1.75 \% / y r$ growth and 2-year out-

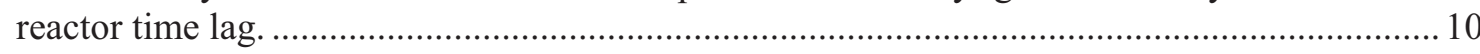

Figure 1-7. Preliminary estimates of uranium consumption with $1.75 \% / \mathrm{yr}$ growth and 11 -year

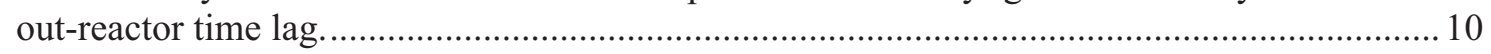

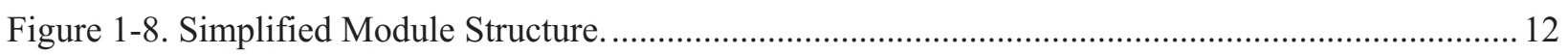

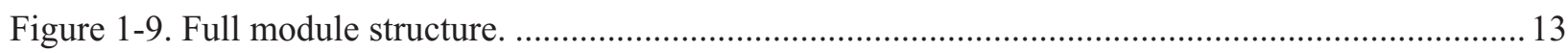

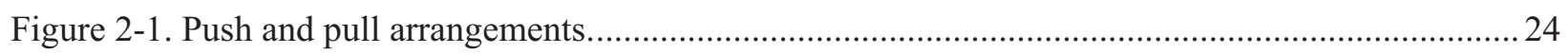

Figure 2-2. Periodic Table as seen from fuel cycle system analysis perspective.[Piet2009]...................26

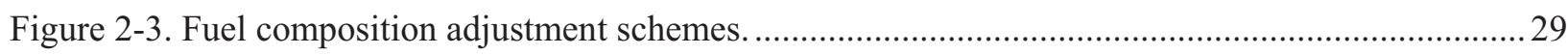

Figure 3-1. Heat generation rate of used fuel as function of LWR UOX burnup.................................... 36

Figure 3-2. Heat generation rate of used fuel as function of LWR fuel.................................................. 36

\section{TABLES}

Table 1-1. Static Equilibrium, Dynamic Equilibrium, and Dynamic Analyses....................................... 4

Table 1-2. Percent Fast Reactor Generation of Electricity, Out-Reactor Time Lag of 2 Years................... 7

Table 1-3. Percent Fast Reactor Generation of Electricity, Out-Reactor Time Lag of 11 Years................. 7

Table 1-4. Uranium Improvement Versus Once Through at 1.75\%/yr Growth and $\mathrm{CR}=1.75$.................. 9

Table 1-5. Candidate Fuel Cycles Considered in this Study .................................................................. 14

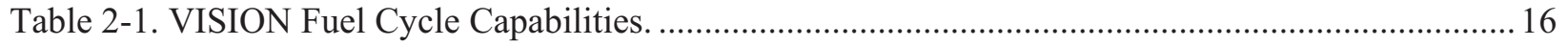

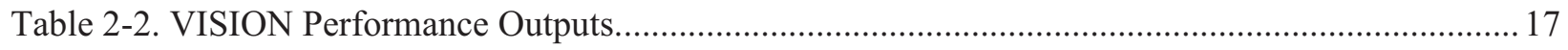

Table 2-3. Tracked Isotopes and Chemical Elements [Piet2009] ...........................................................2

Table 2-4. Hypothetical Categories of Economic Analyses. ................................................................... 30

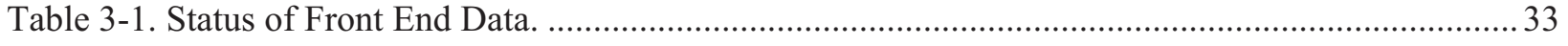

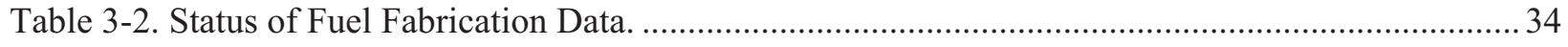

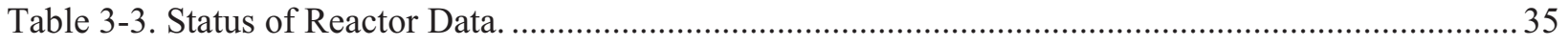

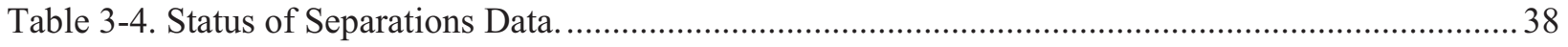

Table 3-5. Status of Waste Management Data.......................................................................................... 39 
Assessment for Dynamic Analyses

June 30, 2011

vii

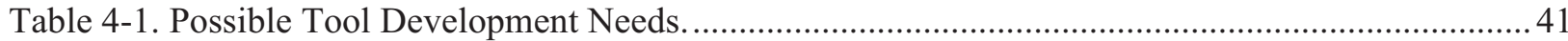




\section{ACRONYMS}

\begin{tabular}{|c|c|}
\hline $\mathrm{A} / \mathrm{B} / \mathrm{C}$ & $\begin{array}{l}\text { Class A, B, or C wastes as defined by U.S. regulation 10CFR61 are generally } \\
\text { acceptable for disposal near-surface. }\end{array}$ \\
\hline ADS & Accelerator driven system \\
\hline AMUSE & A chemistry separation model, used here as an example \\
\hline ANL & Argonne National Laboratory \\
\hline BR & Fissile breeding ratio (similar but not identical to conversion ratio, $\mathrm{CR}$ ) \\
\hline $\mathrm{BU}$ & Burnup (MWth-day/kg-iHM or equivalently GWth-day/tonne-iHM) \\
\hline BWR & Boiling water reactor \\
\hline COEX & Co-extraction of $\mathrm{U}$ and $\mathrm{Pu}$ \\
\hline CORAIL & 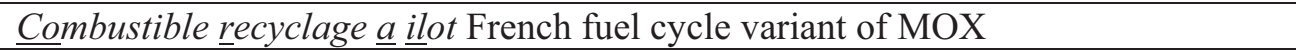 \\
\hline $\mathrm{CR}$ & Transuranic conversion ratio (similar but not identical to breeding ratio, BR) \\
\hline $\mathrm{CY}$ & Calendar year \\
\hline $\mathrm{DU}$ & Depleted uranium \\
\hline EBR & Experimental Breeder Reactor \\
\hline EDS & Externally driven system, such as fission-fusion hybrid or accelerator driven system \\
\hline EFPD & Effective full power days \\
\hline EFPY & Effective full power years $=$ capacity factor times calendar years \\
\hline EU & Enriched uranium \\
\hline F-R & Fuel cycle designator for Full Recycle [ISEP2011] \\
\hline FCT & Fuel Cycle Technologies program \\
\hline FIT & Fuel-cycle Integration \& Tradeoffs model \\
\hline FP & Fission product \\
\hline FR & Fast reactor or fast reactor fuel \\
\hline FR-NpPu & Fast reactor fuel with $\mathrm{Np}, \mathrm{Pu}$, and no other transuranic elements \\
\hline FR-NpPuAm & Fast reactor fuel with $\mathrm{Np}, \mathrm{Pu}, \mathrm{Am}$, and no other transuranic elements \\
\hline $\mathrm{FR}-\mathrm{Pu}$ & Fast reactor fuel and no other transuranic elements \\
\hline FR-TRU & Fast reactor fuel with all the transuranic elements \\
\hline GTCC & Greater than Class $\mathrm{C}$ waste class \\
\hline GWe & Gigawatt-electric (one billion watts of electricity) \\
\hline GWth & Gigawatt-thermal (one billion watts of heat) \\
\hline HEU & Highly enriched uranium \\
\hline HTGR & High temperature gas reactor \\
\hline HWR & Heavy water reactor \\
\hline iHM & Initial heavy metal \\
\hline IMF & Inert matrix fuel (uranium free) \\
\hline IMF-NpPu & Inert matrix fuel with $\mathrm{Np}, \mathrm{Pu}$, and no other transuranic elements \\
\hline IMF-NpPuAm & Inert matrix fuel with $\mathrm{Np}, \mathrm{Pu}, \mathrm{Am}$, and no other transuranic elements \\
\hline IMF-Pu & Inert matrix fuel and no other transuranic elements \\
\hline IMF-TRU & Inert matrix fuel with all the transuranic elements \\
\hline LLW & Low-level waste \\
\hline LWR & Light water reactor \\
\hline $\mathrm{M}-\mathrm{O}$ & Fuel cycle designator for modified open [ISEP2011] \\
\hline MCNP & Monte Carlo N-Particle reactor physics model \\
\hline MOX & Mixed oxide fuel \\
\hline $\mathrm{MOX}-\mathrm{NpPu}$ & Mixed oxide fuel with $\mathrm{Np}, \mathrm{Pu}$, and no other transuranic elements \\
\hline MOX-NpPuAm & Mixed oxide fuel with $\mathrm{Np}, \mathrm{Pu}, \mathrm{Am}$, and no other transuranic elements \\
\hline
\end{tabular}




\begin{tabular}{|c|c|}
\hline $\mathrm{MOX}-\mathrm{Pu}$ & Mixed oxide fuel with $\mathrm{Pu}$ and no other transuranic elements \\
\hline MOX-TRU & Mixed oxide fuel with all the transuranic elements \\
\hline MRS & Monitored Retrievable Storage \\
\hline MSR & Molten salt reactor \\
\hline MWe & Megawatt-electric (one million watts of electricity) \\
\hline MWth & Megawatt-thermal (one million watts of heat) \\
\hline NA & Not applicable \\
\hline NU & Natural uranium \\
\hline ORIGEN & Isotope depletion model \\
\hline ORNL & Oak Ridge National Laboratory \\
\hline $\mathrm{O}-\mathrm{T}$ & Fuel cycle designator for Once Through [ISEP2011] \\
\hline PWR & Pressurized water reactor \\
\hline PUREX & Plutonium-Uranium Extraction separation process \\
\hline RU & Recovered uranium \\
\hline SNF & Spent nuclear fuel \\
\hline $\mathrm{t}$ & Time \\
\hline $\mathrm{T}_{1 / 2}$ & Halflife \\
\hline TBD & To be determined \\
\hline ThOX & Thorium oxide \\
\hline Tonne & $1000 \mathrm{~kg}$, metric ton \\
\hline TRU & Transuranic elements \\
\hline $\mathrm{UCO}$ & Uranium oxycarbide fuel \\
\hline $\mathrm{UOX}$ or $\mathrm{UO}_{2}$ & Uranium oxide fuel \\
\hline UOX-nn & Uranium oxide fuel with nn MWth-day/kg-iHM burnup \\
\hline UREX & Uranium Extraction separation process \\
\hline VHTR & Very high temperature reactor \\
\hline VISION & Verifiable Fuel Cycle Simulation dynamic fuel cycle model \\
\hline $\mathrm{W}$ & Watt \\
\hline W.F. & Wasteform \\
\hline W.D. & Waste disposition \\
\hline Yr & $\begin{array}{l}\text { Year (generally "year" is calendar year except when the differentiation between } \\
\text { calendar year and effective full power years is obvious) }\end{array}$ \\
\hline $\mathrm{Zr}$ & Zirconium \\
\hline$\sigma$ & Cross section \\
\hline
\end{tabular}




\section{SYSTEM ANALYSIS CAMPAIGN ASSESSMENT OF TOOLS AND DATA FOR SYSTEM- LEVEL DYNAMIC ANALYSES}

\section{INTRODUCTION}

Models are necessarily incomplete simulations of reality. In a sense, it is impossible to definitively assess tools and data for system-level dynamic analyses because the purposes, the needs, of those analyses evolve. Therefore, this report explores four questions.

- First, what are the benefits of dynamic analyses versus the traditional static analysis? What knowledge of candidate fuel cycles can be gained through dynamic analysis? What questions can be better answered doing dynamic analyses?

- Second, what is the status of tools and data associated with dynamic analyses?

- Third, given what is known about the FCT program, what can we reasonably deduce are needs? Examples are tools and data for thorium fuel cycles and more specificity on waste management. This type of information is an input to R\&D and for data collection for future comparisons and selection among fuel cycle options.

- Fourth, necessarily less complete, what other needs might exist? This is not intended to be a laundry list, but rather as an aid to the reader, in part by differentiating what does and does not exist in existing tools.

The first set of questions is covered in Chapter 1. The other questions are addressed in Chapter 2, Tools and Chapter 3, Data. In this report, "data" means experimental data, data from more detailed theoretical or empirical calculations on technology performance, and assumptions such as the earliest date a technology can be deployed.

Figure 1-1 shows a pyramid of computer models in the fuel cycle program. The concept for this pyramid was started by Kemal Pasamehmetoglu, when many of the implied types of analyses and models did not exist. Today, the pyramid's models exist. At the top are models that look at nuclear energy in the context of other energy sources and of energy needs - primarily electricity. The bottom two layers are the preview of individual Campaigns in the fuel cycle program - reactors/reactor physics, separation, fuels, waste forms, and waste disposal.

The second and third layers in the pyramid are models created by the Systems Analysis Campaign. VISION 3 [Jacobson2010, Jacobson2011] models the time-dependent dynamics of nuclear systems, including technology deployments, timing, sequencing, and evolution. It addresses how a nuclear system can evolve with time and therefore where problems can occur, what fuels and wastes are made, what the reactor mix may be, etc. FIT 2 [Piet2011] is a complementary model that addresses how a nuclear system changes in a quasi-steady state manner due to a chemical change in the system, e.g., how impurities accumulate in fuel or in wastes.

This report primarily addresses the workhorse model for dynamic analyses, VISION. However, some of the issues that FIT can address may be candidates for time-dependent treatment in VISION. 


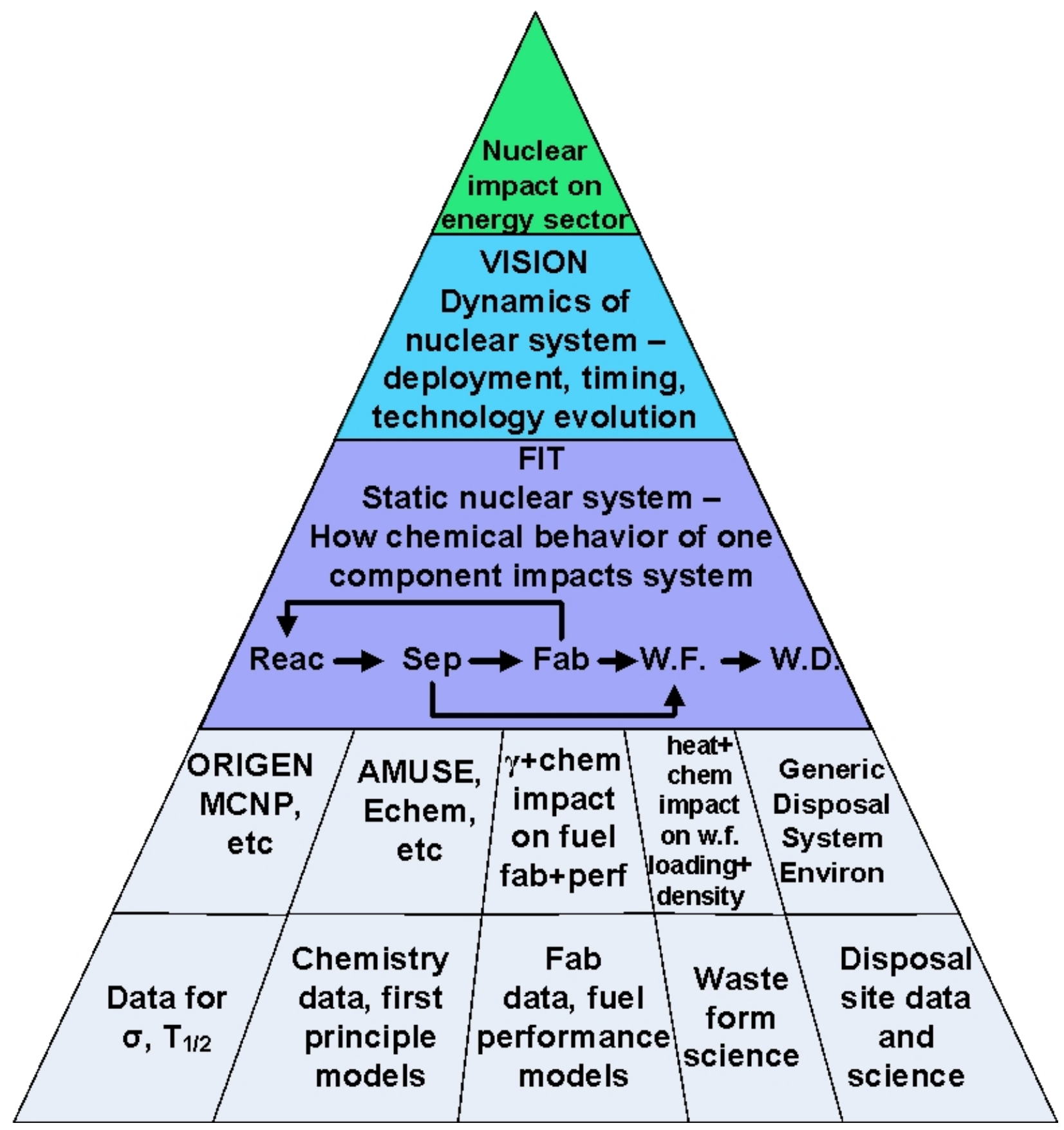

Figure 1-1. Pyramid of types of computer models.

\subsection{What Are Dynamic Analyses?}

Dynamic analyses track how a system can change as a result of changes within functions (performance changes) or changes in relationships among functions. Thus, dynamic analyses are all about what does not change, what does change, how quickly changes occur, what changes as a result of changes, etc. Dynamic analyses of fuel cycles address both mass and information flows.

To go further, a few definitions are required: 
- Reactor equilibrium is a reactor physics concept in which the conditions in the reactor for a given refueling are in equilibrium with the incoming fuel. Thus, a reactor goes through initial nonequilibrium core loads, a phase in which core re-loads are close to equilibrium, and then a phase approaching reactor retirement in which core loads again are quite non-equilibrium as fuel loads do not need to last the normal fuel lifetime. This type of equilibrium is not addressed in this study.

- Fuel cycle equilibrium is a systems concept in which the conditions in a fuel cycle involving many reactors, fuel fabrication, and possibly fuel separation are in equilibrium. When a new fuel type or new separation technology is added to a system, first individual reactors and then the entire system tries to become in equilibrium.

- Reactor recycle pass means how many times fuel material has been recycled. In VISION, pass0 means unrecycled material. Since thorium fuel cycles are not an option in the model, pass 0 fuel is necessarily uranium-based. In VISION, pass-N fuel means recycled material, starting with pass 1, the first time material is recycled. Material separated and recycled from passN is recycled as passN +1 . In the current version of VISION, the highest pass is pass5. Material recycled from pass5 is recycled back into pass5. Thus, VISION does not model changes in recycled fuel after five recycle passes. Note that all recycle passes are assumed to be in reactor equilibrium. For example, the reactor data are for reactors that are in equilibrium with first-time-recycled material, even though it may actually take several refueling before such reactors achieve equilibrium compositions.

- Transuranic (TRU) conversion ratio (CR) is the creation of TRU isotopes divided by the destruction of TRU isotopes.

- Fissile breeding ratio (BR) is the same as CR except the denominator and numerator are fissile content, not TRU.

- Output/input composition ratio is the ratio of the output/input composition of either TRU or fissile isotopes, as stated.

The CR (or BR) versus output/input composition ratio both have their uses, but it is critical (literally and figuratively) to understand the difference.

$$
\begin{aligned}
& C R=\frac{\text { delta gain }}{\text { delta loss }} \\
& \frac{\text { Output }}{\text { Input }}=\frac{\text { Input }+ \text { delta }}{\text { Input }}=1+\frac{\text { delta }}{\text { Input }}=1+\frac{\text { delta gain }- \text { delta loss }}{\text { Input }}
\end{aligned}
$$

The only times CR and the output/input composition ratio are numerically equal are when either

input $=$ deltaloss, in other words, when the entire input material is not longer what it started as

Or

delta gain $=$ delta loss, and thus $C R=\frac{\text { Output }}{\text { Input }}=1$ and there is no net change.

Otherwise, CR and output/input composition ratios will differ; examples appear later in Chapter 1.

Table 1-1 provides definitions for static equilibrium, dynamic equilibrium, and dynamic analyses in the context of fuel cycle systems. As one moves from static equilibrium to dynamic equilibrium, the required tools, input, and complexity change. Equilibrium calculations can be done with straightforward 
spreadsheets. Dynamic analyses require a computer model that can consider the parts of the fuel cycle of interest, which might be the entire fuel cycle, and the various constraints on mass flows and how the parts of the fuel cycle function. As one moves from static equilibrium to dynamic analyses, the type of information provided increases as well. Table 1-1 provides examples, some of which are fleshed out in the next subsection.

Table 1-1. Static Equilibrium, Dynamic Equilibrium, and Dynamic Analyses.

\begin{tabular}{|c|c|c|c|}
\hline & Static equilibrium & Dynamic equilibrium & Dynamic Analyses \\
\hline Definition & $\begin{array}{l}\text { The time-independent } \\
\text { behavior of a fuel cycle } \\
\text { assuming all components } \\
\text { are unchanging internally } \\
\text { and with regard to each } \\
\text { other, and with no time } \\
\text { lags in the system. }\end{array}$ & $\begin{array}{l}\text { The time-independent } \\
\text { behavior of a fuel cycle } \\
\text { assuming all components are } \\
\text { unchanging internally and } \\
\text { with regard to each other. } \\
\text { (Time lags are included but } \\
\text { are kept constant.) }\end{array}$ & $\begin{array}{l}\text { The time-dependent behavior of } \\
\text { a fuel cycle }\end{array}$ \\
\hline $\begin{array}{l}\text { Typical } \\
\text { inputs }\end{array}$ & $\begin{array}{l}\text { - Fuel burnup } \\
\text { - Input and output fuel } \\
\text { composition } \\
\text { - TRU conversion ratio } \\
\text { - Fissile breeding ratio } \\
\text { - Thermal efficiency } \\
\text { - Capacity factor } \\
\text { - Average cost of a } \\
\text { substance or service, } \\
\$ / k g\end{array}$ & $\begin{array}{l}\text { Static equilibrium plus ... } \\
\text { - Growth rate of nuclear } \\
\text { energy } \\
\text { - In-reactor time lag = fuel } \\
\text { residence time } \\
\text { - Out-reactor time lag = time } \\
\text { in wet storage + time in } \\
\text { separation + time in } \\
\text { fabrication } \\
\text { - Other time lags as relevant }\end{array}$ & $\begin{array}{l}\text { Dynamic equilibrium plus ... } \\
\text { - Sequence of technology } \\
\text { changes and deployments } \\
\text { - Time when new technologies } \\
\text { are deployed, e.g., repository, } \\
\text { new reactors, separation plants } \\
\text { - Constraints on new technology } \\
\text { deployment (e.g. constrained } \\
\text { construction during first } \\
\text { decades) } \\
\text { - Facility lifetimes, esp. reactors } \\
\text { - Retirement profile of facilities } \\
\text { existing at start of simulation } \\
\text { - Used fuel inventory } \\
\text { accumulating before separation } \\
\text { starts } \\
\text { - Capital cost } \\
\text { - Operating and maintenance } \\
\text { cost }\end{array}$ \\
\hline $\begin{array}{l}\text { Possible } \\
\text { outputs }\end{array}$ & $\begin{array}{l}\text { - For synergistic systems, } \\
\text { the ratio of one reactor } \\
\text { type to another at static } \\
\text { equilibrium } \\
\text { - Cost comparisons }\end{array}$ & $\begin{array}{l}\text { Same as static equilibriums } \\
\text { but more realistic answers }\end{array}$ & $\begin{array}{l}\text { Dynamic equilibrium plus ... } \\
\text { - When benefits of new } \\
\text { technologies and fuel cycles } \\
\text { manifest } \\
\text { - Identification of choke points } \\
\text { - Peak inventory of used fuel } \\
\text { - Cash flows }\end{array}$ \\
\hline
\end{tabular}

\subsection{Why Do We Care?}

Many considerations of fuel cycle performance can only be estimated via dynamic analyses. Decisionmakers tend to want to know what costs (economic and otherwise) will be required and when, and what benefits will manifest and when. Indeed, people tend to prefer arrangements that defer costs and accelerate benefits. Only dynamic analyses can answer such questions. 
In general, the estimated performance of candidate fuel cycles is better when analyzed as static equilibrium and worse when all the constraints and realities of dynamic analyses are included. The impacts of delays inherent in the system, dynamic feedback tend to depress the results. Thus, if the FCT program wants to avoid overpromising what new fuel cycles can do, dynamic analyses are required.

Experience indicates that fuel cycles differ in the degree to which the output for fuel cycle performance changes as one shifts from a static viewpoint to a dynamic viewpoint. For example, it is obvious from static equilibrium calculations that a fuel cycle with burner fast reactors (TRU conversion ratio $<1$ ) using the separated TRU from LWRs will use little $(\leq 1 \%)$ of the theoretical energy content of uranium ore.[Bays2010] Static equilibrium calculations also indicate that a fuel cycle with breeder fast reactors (TRU conversion ratio > 1) can achieve 100\% uranium utilization, as illustrated in Figure 1-2.[Piet2011a] Except as otherwise noted, the reactor physics data in this and subsequent examples come from Ed Hoffman for fast reactors and John Stillman for LWRs.[Hoffman2006, Hoffman2007, Hoffman2009, Stillman2004]

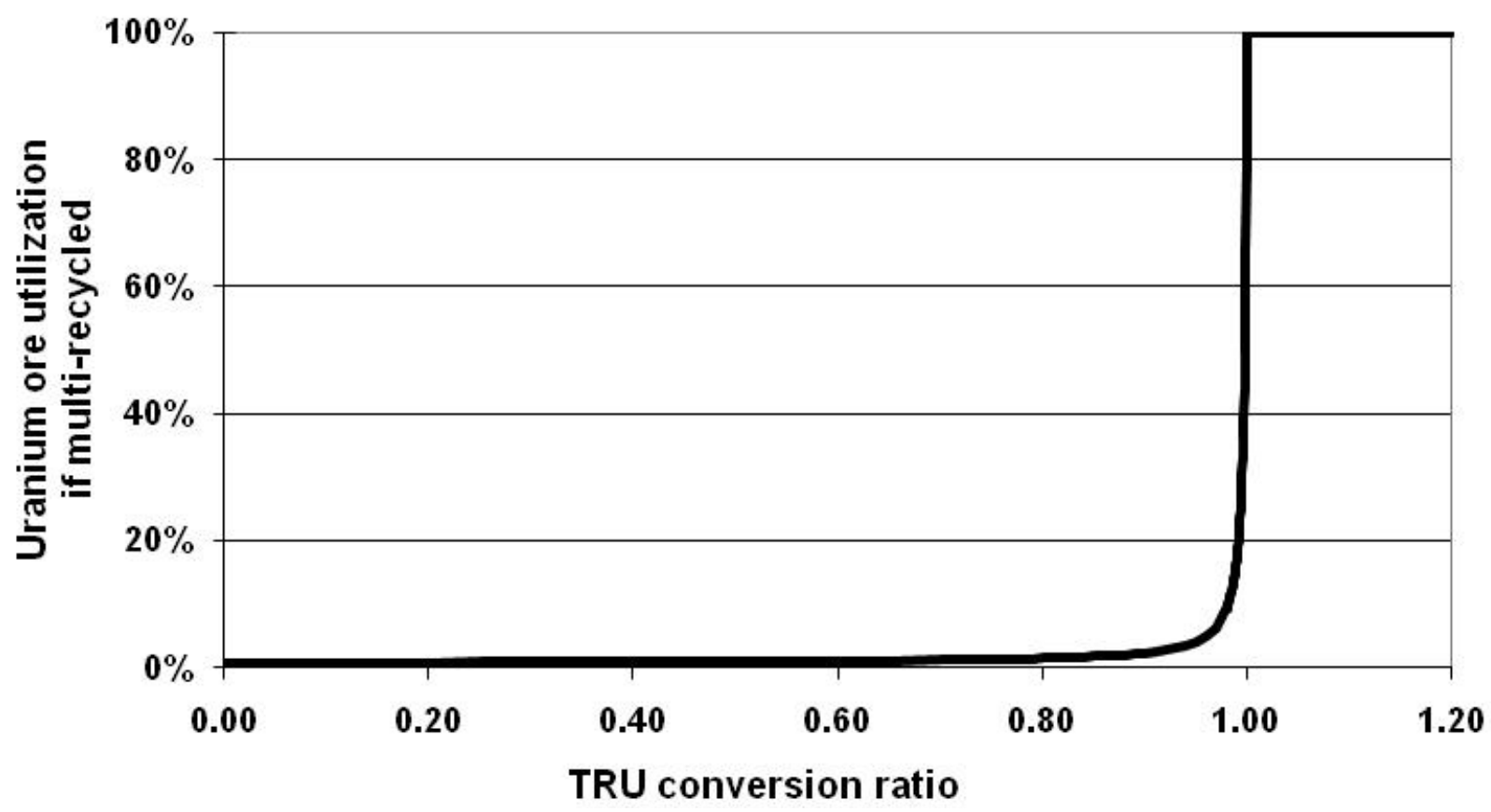

Figure 1-2. Uranium utilization at static equilibrium as function of TRU conversion ratio.

The static equilibrium treatment says that any breeder (TRU CR $>1$ ) would get $\sim 100 \%$ uranium utilization, but a simple dynamic equilibrium treatment shows that this is not true. A dynamic equilibrium treatment accounts for the growth in the reactor fleet during the time TRU is turning around, in-reactor plus out-reactor (i.e., wet storage, dry storage, separations, fuel fabrication). Figure 1-3 [Piet2011a] shows the sustainable growth rate for a pure fast reactor system as function of turnaround time and output/input composition ratio. 


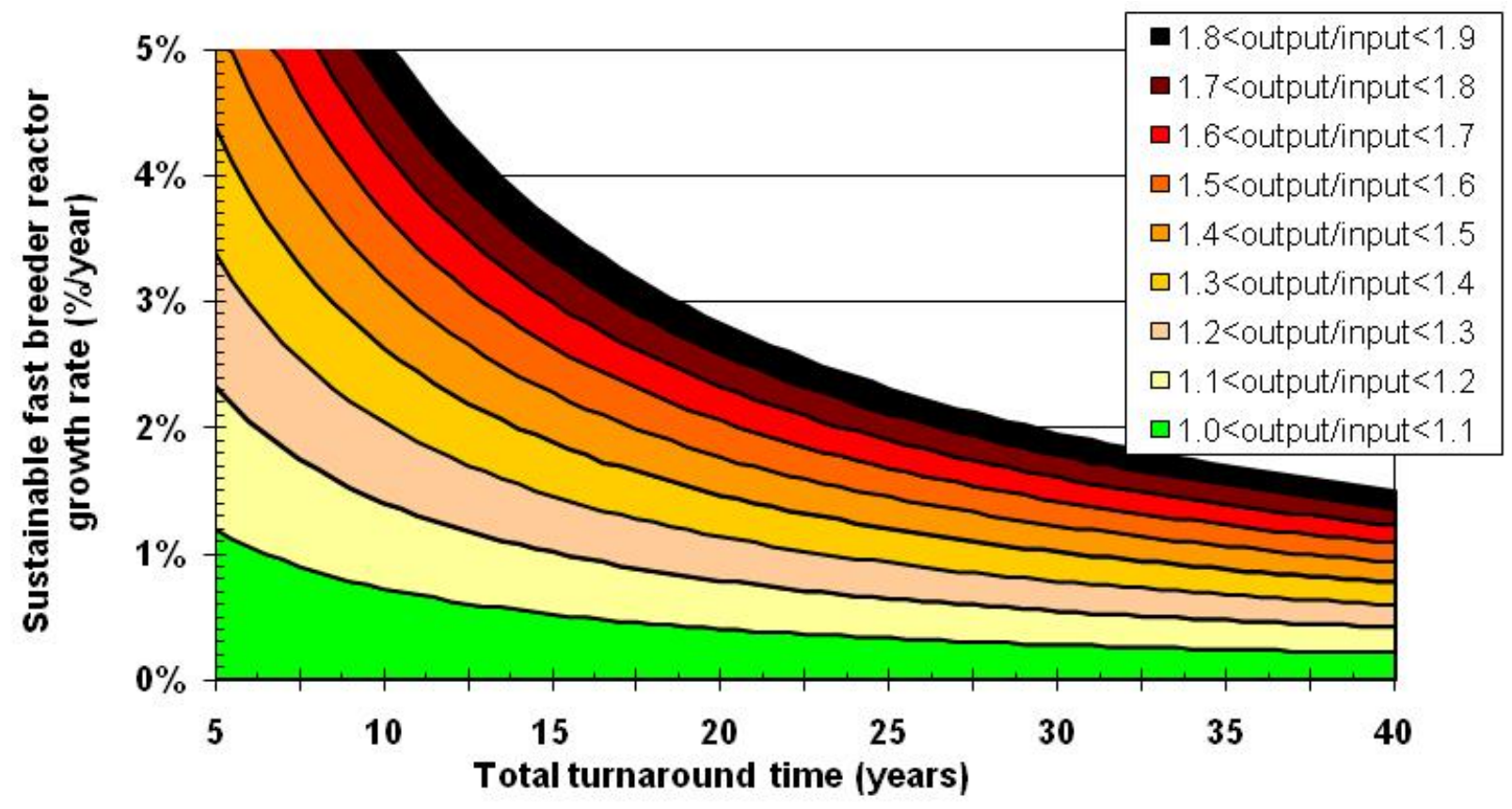

Figure 1-3. Sustainable fast breeder reactor growth rate as function of total turnaround time (in-reactor plus out-reactor time lags).

As an example, consider two illustrative cases from the DSARR study.[Dixon2008]

- Onsite recycling -4 years minimum in-reactor time +1 -year wet storage +0.5 -year in separation $+0.5-\mathrm{yr}$ in fuel fabrication for a total minimum turnaround of 6 years

- Offsite recycling -4 years in-reactor +10 -year wet storage +0.5 -year in separation +0.5 -year in fuel fabrication for a total minimum turnaround of 15 years.

Assume an output/input ratio of 1.2 . Then, the sustainable growth rate for onsite is $2.05 \% /$ year but only $1.30 \%$ year for offsite. The nominal growth rate in DSARR was $1.75 \% / y e a r$. That is, at the nominal DSARR growth rate, an offsite recycling scheme does not enable a pure fast reactor fleet with an output/input ratio of 1.2. An output/input ratio of about 1.3 would be required, which is an aggressive breeder.

Now consider dynamic analyses. Tables 1-2 and 1-3 show the percent fast reactor generation of electricity from three perspectives at a growth rate of $1.75 \% / y e a r-$ static equilibrium, dynamic equilibrium, and dynamic analyses. The only difference between the two tables is the out-reactor time lag, 2 versus 11 years. The static equilibrium results are the same. The dynamic equilibrium calculations are done in two ways - using the startup recycle composition when fast reactors are fed solely by used LWR fuel and equilibrium recycle composition when fast reactors are fed by a combination of their equilibrium composition and (if needed) by used LWR fuel. 
Table 1-2. Percent Fast Reactor Generation of Electricity, Out-Reactor Time Lag of 2 Years

\begin{tabular}{|c|c|c|c|c|c|c|c|c|c|c|}
\hline TRU CR & 0.00 & 0.25 & 0.50 & 0.75 & 1.00 & 1.12 & 1.43 & 1.52 & 1.67 & 1.75 \\
\hline TRU output/input ratio & 0.63 & 0.70 & 0.80 & 0.90 & 1.00 & 1.05 & 1.09 & 1.08 & 1.13 & 1.20 \\
\hline$\% \mathrm{FR}$ at static equilibrium & 23 & 28 & 39 & 59 & 98 & 100 & 100 & 100 & 100 & 100 \\
\hline $\begin{array}{l}\% \mathrm{FR} \text { at dynamic } \\
\text { equilibrium, startup recycle }\end{array}$ & 16 & 19 & 26 & 35 & 50 & 55 & 64 & 64 & 72 & 92 \\
\hline $\begin{array}{l}\text { \% FR at dynamic } \\
\text { equilibrium, equilibrium } \\
\text { pass }\end{array}$ & 14 & 18 & 24 & 35 & 56 & 69 & 100 & 100 & 100 & 100 \\
\hline $\begin{array}{l}\% \text { FR with VISION } \\
\text { version } 3.4 \text { in } 2160-2200 \\
\text { (effective equilibrium } \\
\text { achieved) }\end{array}$ & 15 & 18 & 25 & 32 & 38 & 46 & 59 & 57 & 81 & 100 \\
\hline
\end{tabular}

Table 1-3. Percent Fast Reactor Generation of Electricity, Out-Reactor Time Lag of 11 Years.

\begin{tabular}{|l|r|r|r|r|r|r|r|r|r|r|r|}
\hline TRU CR & 0.00 & 0.25 & 0.50 & 0.75 & 1.00 & 1.12 & 1.43 & 1.52 & 1.67 & 1.75 \\
\hline TRU output/input ratio & 0.63 & 0.70 & 0.80 & 0.90 & 1.00 & 1.05 & 1.09 & 1.08 & 1.13 & 1.20 \\
\hline \% FR at static equilibrium & 23 & 28 & 39 & 59 & 98 & $\mathbf{1 0 0}$ & $\mathbf{1 0 0}$ & $\mathbf{1 0 0}$ & $\mathbf{1 0 0}$ & $\mathbf{1 0 0}$ \\
\hline $\begin{array}{l}\text { \% FR at dynamic } \\
\text { equilibrium, startup recycle }\end{array}$ & 14 & 16 & 20 & 25 & 31 & 34 & 34 & 35 & 39 & 44 \\
\hline $\begin{array}{l}\text { \% FR at dynamic } \\
\text { equilibrium, equilibrium } \\
\text { pass }\end{array}$ & 12 & 14 & 18 & 25 & 34 & 40 & 46 & 48 & 56 & 69 \\
\hline $\begin{array}{l}\text { \% FR with VISION } \\
\text { version 3.4 in 2190-2200 } \\
\text { (CR>1 cases still climbing, } \\
\text { not yet equilibrium) }\end{array}$ & 13 & 16 & 20 & 24 & 27 & 31 & 33 & 34 & 41 & 57 \\
\hline
\end{tabular}

Consistent with Figure 1-3, the 2-year out-reactor case can go to $100 \%$ fast reactors for four of the breeder cases, but the 11-year out-reactor case cannot, at the growth rate of $1.75 \% /$ year.

The two tables also provide VISION results. At low CR, the results are similar to the dynamic equilibrium results. As CR increases, dynamic equilibria and VISION results sometimes diverge. There are three reasons. First, there are second-order effects that are not included in the spreadsheet-based dynamic equilibria, e.g., VISION keeps used fuel at least one time step in dry storage in the process of moving fuel to separations. Second, some of the cases are not at dynamic equilibrium in the VISION calculations, even by 2200, that is best seen in Figures 1-4 and 1-5. Third, the current VISION prediction and ordering algorithm is somewhat conservative. 


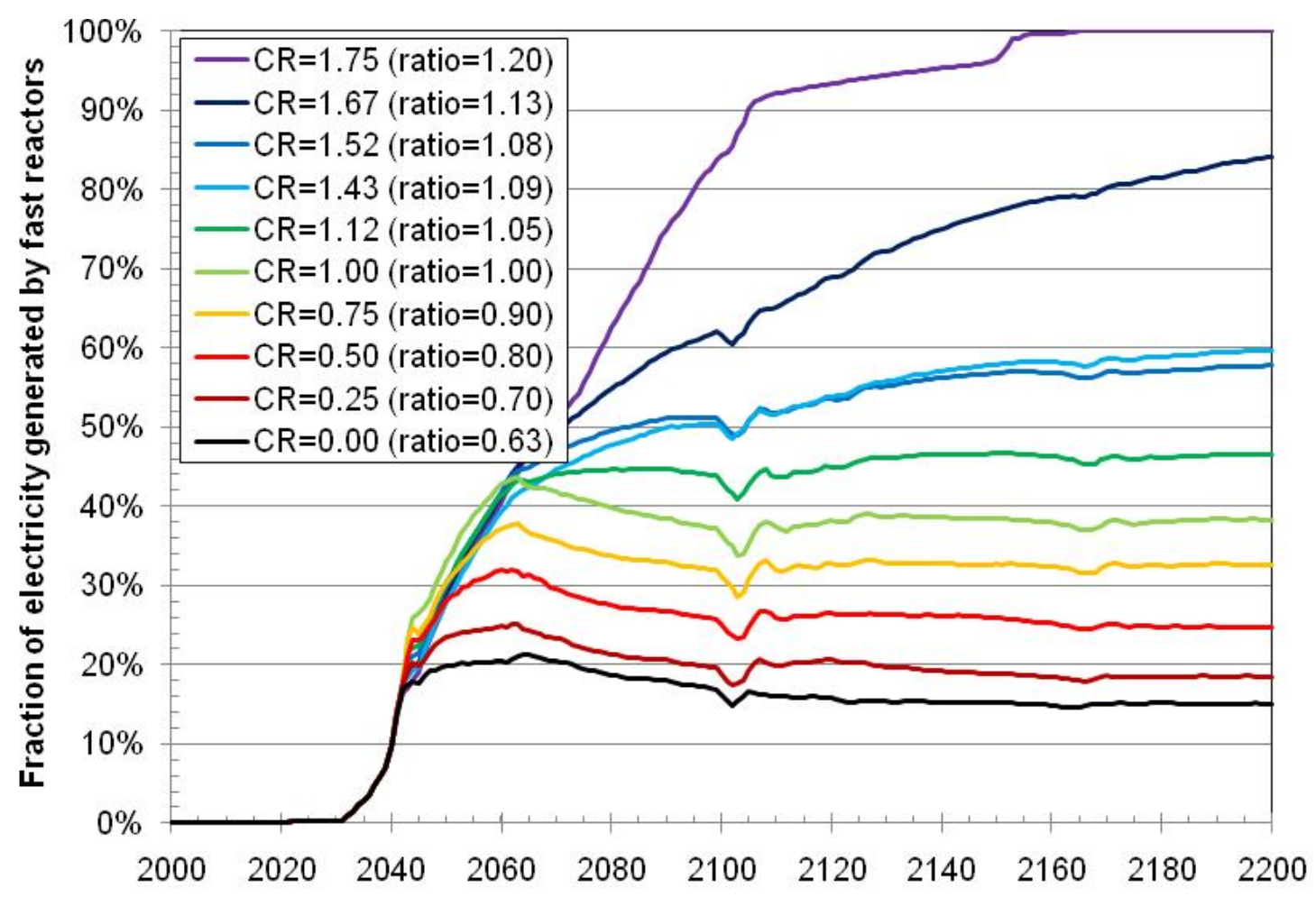

Figure 1-4. Preliminary estimates of percent electricity from fast reactors with $1.75 \% / \mathrm{yr}$ growth and 2-yr out-reactor time lag.

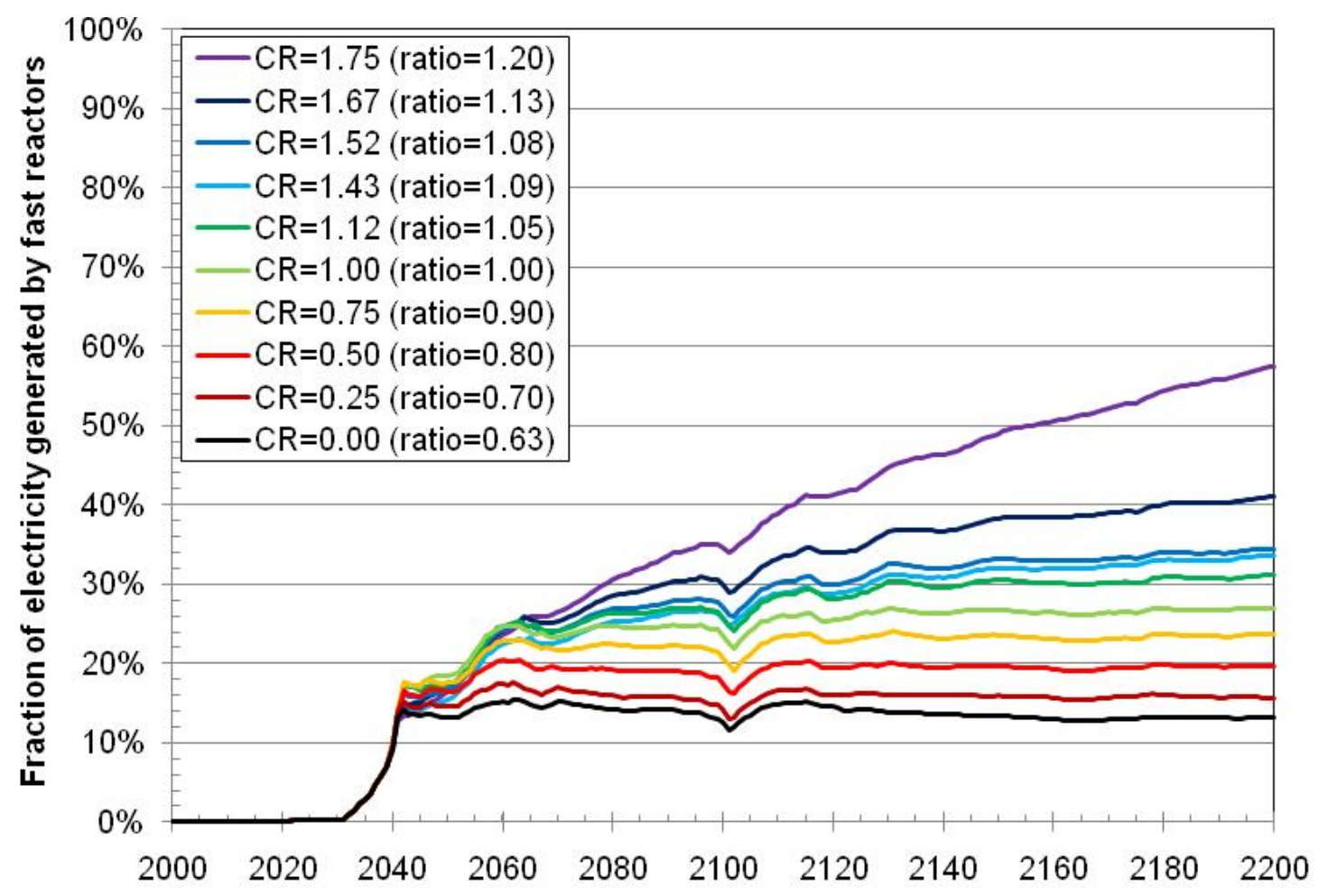

Figure 1-5. Preliminary estimates of percent electricity from fast reactors with $1.75 \% / \mathrm{yr}$ growth and $11-\mathrm{yr}$ out-reactor time lag. 
Remember that the only difference between Figure 1-4 and 1-5 is the out-reactor time lag. Changing from 2 to 11 years (1 versus 10 years in wet storage) not only changes the systems' performance but changes when the performance reaches a type of equilibrium.

Of course, the above example only shows one parameter, the percent of electricity from fast reactors. Figures 1-6 and 1-7 shows the uranium ore consumption for the same cases. Growth rate is $1.75 \% / y e a r$. The consumption is solely for the U.S. Table 1-4 summarizes some of the results for the $\mathrm{CR}=1.75$ breeder.

Table 1-4. Cumulative Uranium Improvement Versus Once Through at 1.75\%/yr Growth and CR=1.75

\begin{tabular}{|l|c|c|}
\hline & Onsite & Offsite \\
\hline Minimum time in wet storage (yr) & 1 & 10 \\
\hline Time in separation $(\mathrm{yr})$ & 0.5 & 0.5 \\
\hline Time in fabrication $(\mathrm{yr})$ & 0.5 & 0.5 \\
\hline 2000 to 2100 & $2.0 \mathrm{x}$ & $1.3 \mathrm{x}$ \\
\hline 2000 to 2200 & $10 \mathrm{x}$ & $1.9 \mathrm{x}$ \\
\hline
\end{tabular}

The same facts can lead to different conclusions, but to best see that, one must use the tools and data to do parameter scans, as illustrated here. If, for example one chooses to frame the issue with a time horizon of 2100 and only consider offsite (11-year out-reactor turnaround), one concludes that starting fast breeder reactors on the DSARR time sequence would produce only $30 \%$ uranium savings. That time sequence was a test reactor in 2022, then limited deployment starting in 2032, and full-scale deployment starting in 2042.

But, if one takes a 2200 time horizon and considers onsite options, the uranium savings can rise to 10x. Note that this is still an order of magnitude lower than the classic static equilibrium assessment that a breeder will increase uranium utilization by $100 x$ !

But, the observations go deeper:

- Uranium utilization curves go flat only when a system reaches $\sim 100 \%$ fast reactors.

- For $1.75 \% / y e a r, C R=1.75$, and onsite recycling, it takes a minimum of 70 years to stop using uranium.

- For $1.75 \% / y e a r, ~ C R=1.75$, and offsite recycling, it takes at least three times as long to stop using uranium.

These would seem to be observations one would want in selecting among fuel cycle options and in deciding when one would want to deploy new technologies. 


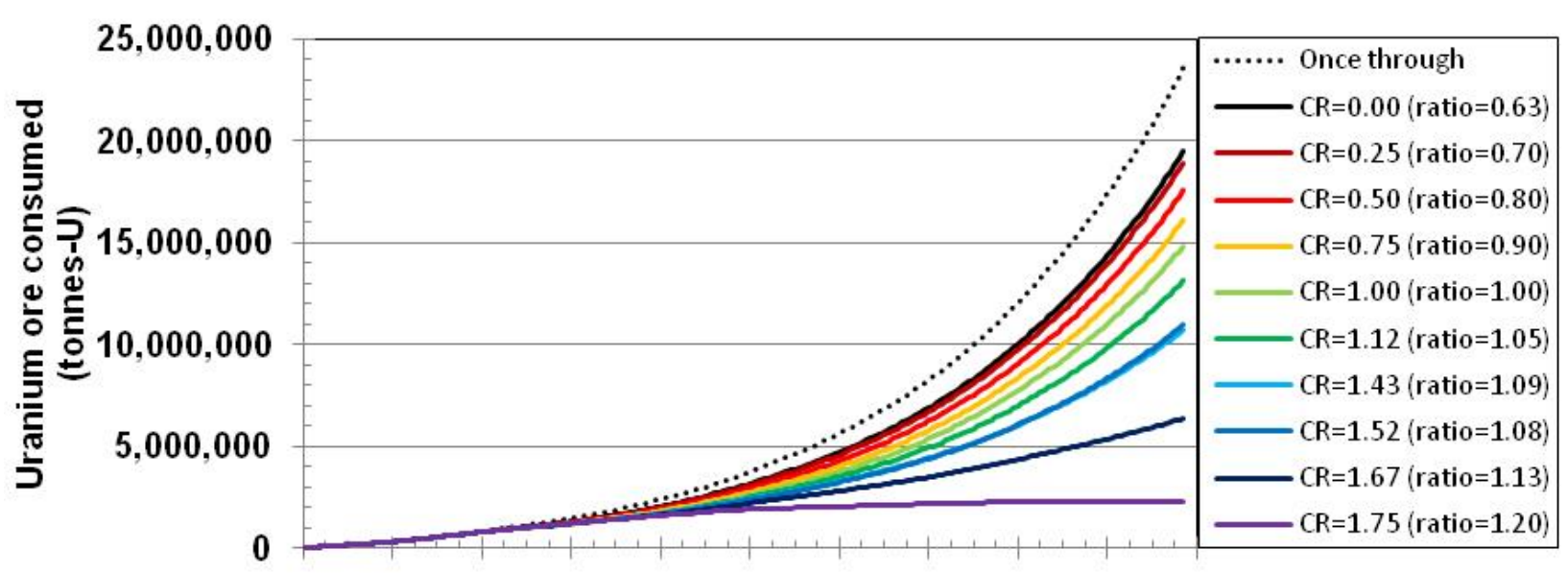

20002020204020602080210021202140216021802200

Figure 1-6. Preliminary estimates of uranium consumption with $1.75 \% / \mathrm{yr}$ growth and 2-year out-reactor time lag.

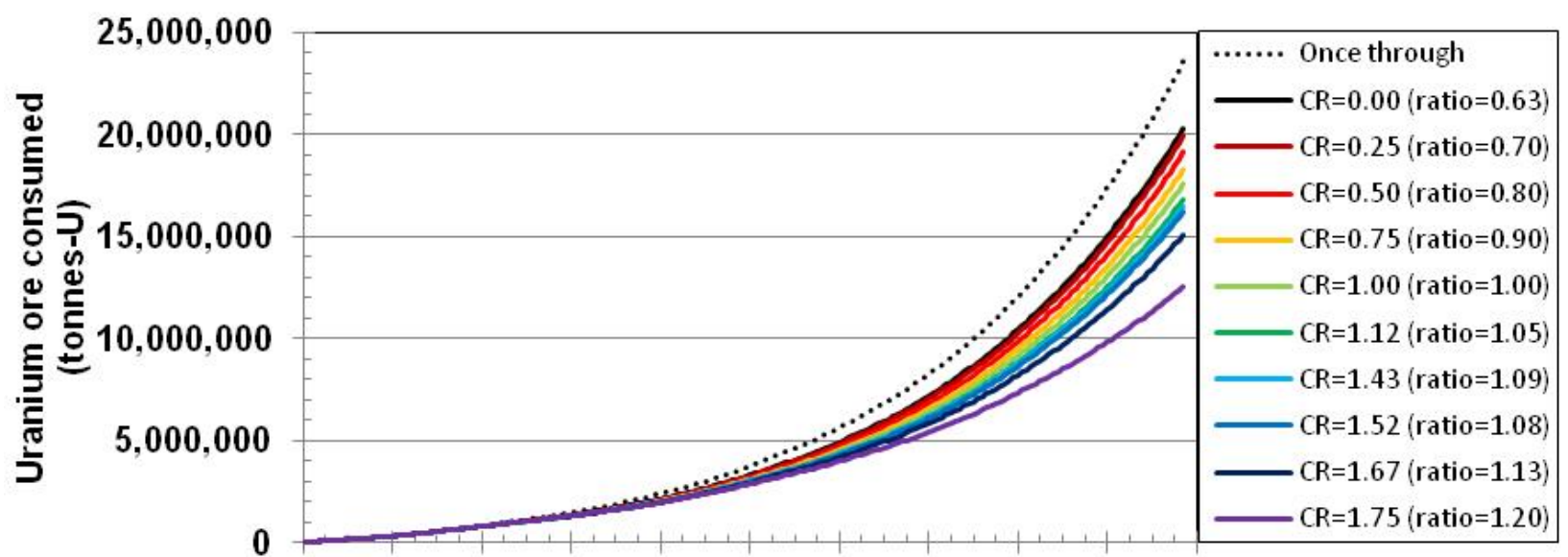

20002020204020602080210021202140216021802200

Figure 1-7. Preliminary estimates of uranium consumption with $1.75 \% / y r$ growth and 11 -year out-reactor time lag.

Another way to look at Figures 1-6 and 1-7 is that these two cases have equivalent uranium savings at $1.75 \%$ year growth rate:

Offsite (11-year out-reactor), $\mathrm{CR}=1.75$ (output/input ratio $=1.20$ )

Onsite (2-year out-reactor), $\mathrm{CR}=1.12$ (output/input ratio $=1.05$ )

This provides a way to trade CR and recycling location.

\subsection{Module Structure}

VISION and some parts of our data bases, notably the Cost Data Base [Shropshire2009] have a module structure. This structure started in 2005 [Jacobson2005, Piet2005, Shropshire2005] and was factored into the software selected to build VISION, how the Cost Data Base was put together, and the input, programming pages, and output structure for VISION.[Jacobson2011] 
Figure 1-8 shows the basic VISION model of the nuclear fuel cycle. The model includes program control and material routing, as well as all the required mass flows. Natural uranium can be enriched, which produces enriched uranium, which goes into fuel fabrication, and depleted uranium (DU), which goes into storage. ${ }^{a}$ (DU) only comes out of storage if used in a reactor. Fuel is transformed (transmuted) in reactors and goes into a storage buffer. Used fuel can be pulled from storage into either separation or disposal. If sent to separations, fuel is transformed (partitioned) into fuel products, recovered uranium, and various categories of waste. Recycled material is stored until used by its assigned reactor type. Note that recovered uranium (RU) is itself often partitioned: some RU flows with recycled transuranic elements, some flows with wastes, and the rest is designated RU. RU comes out of storage if needed to correct the U/TRU ratio in new recycled fuel. Neither RU nor DU is designated as waste.

Figure 1-9 shows the detailed module structure of VISION. It and the Cost Data Base have the same letter designations.

This module structure has stood the test of time and we only modify if absolutely required. We have even learned to use the color scheme in Figures 1-8 and 1-9 as much as possible. We have learned two important lessons that should influence the new fuel cycle models and other tasks.

First, there were functions not adequately appreciated at that time, especially Program control ${ }^{\mathrm{b}}$, Energy Demand, Material routing - if you will - the higher brain functions. The actual parts of the fuel cycle have 1-letter module codes, A to R. Control, interface, and output modules have 2-letter codes, e.g., $\mathrm{WM}=$ waste management and $\mathrm{ED}=$ Energy demand. VISION 3.4 differs from previous versions by reorganization of the pages in the program in Powersim software to better match this module structure. The pages' letter designations match Figure 1-9 and they are listed in order.

Second, the VISION team and economics team did some tweaking on the original definition of modules as we've used them. A few were dropped along the way.

a. Uranium recovered from separations $(\mathrm{RU})$ can be re-enriched using isotope-specific separation factors, but the associated amount of separative work units (SWUs) would not be tracked by the model.

b. By program control, we mean how the user wants the simulation to run, e.g., are reactors to be built to match some energy demand or according to a user-specified number of reactors in each year. 


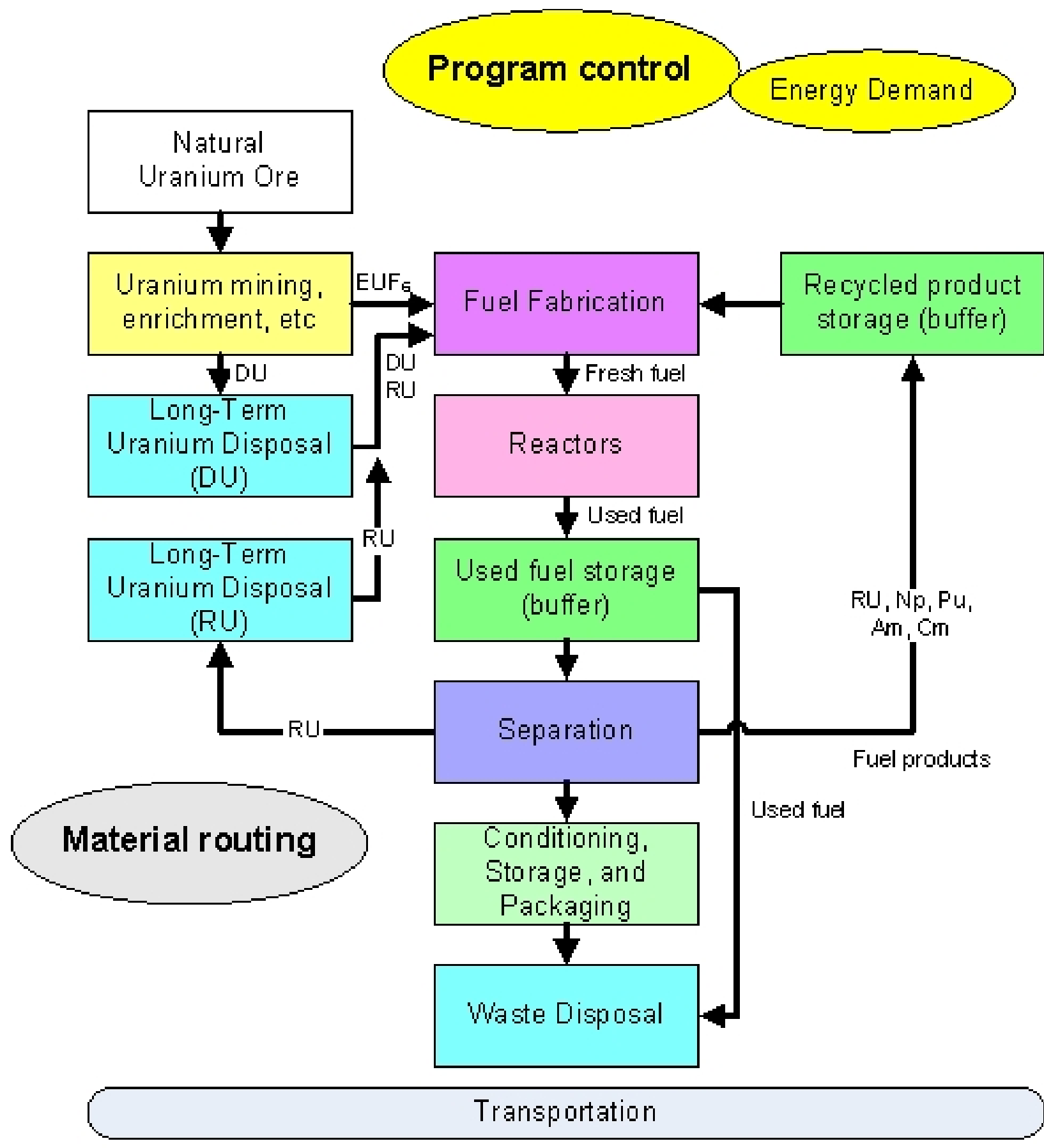

Figure 1-8. Simplified Module Structure. 


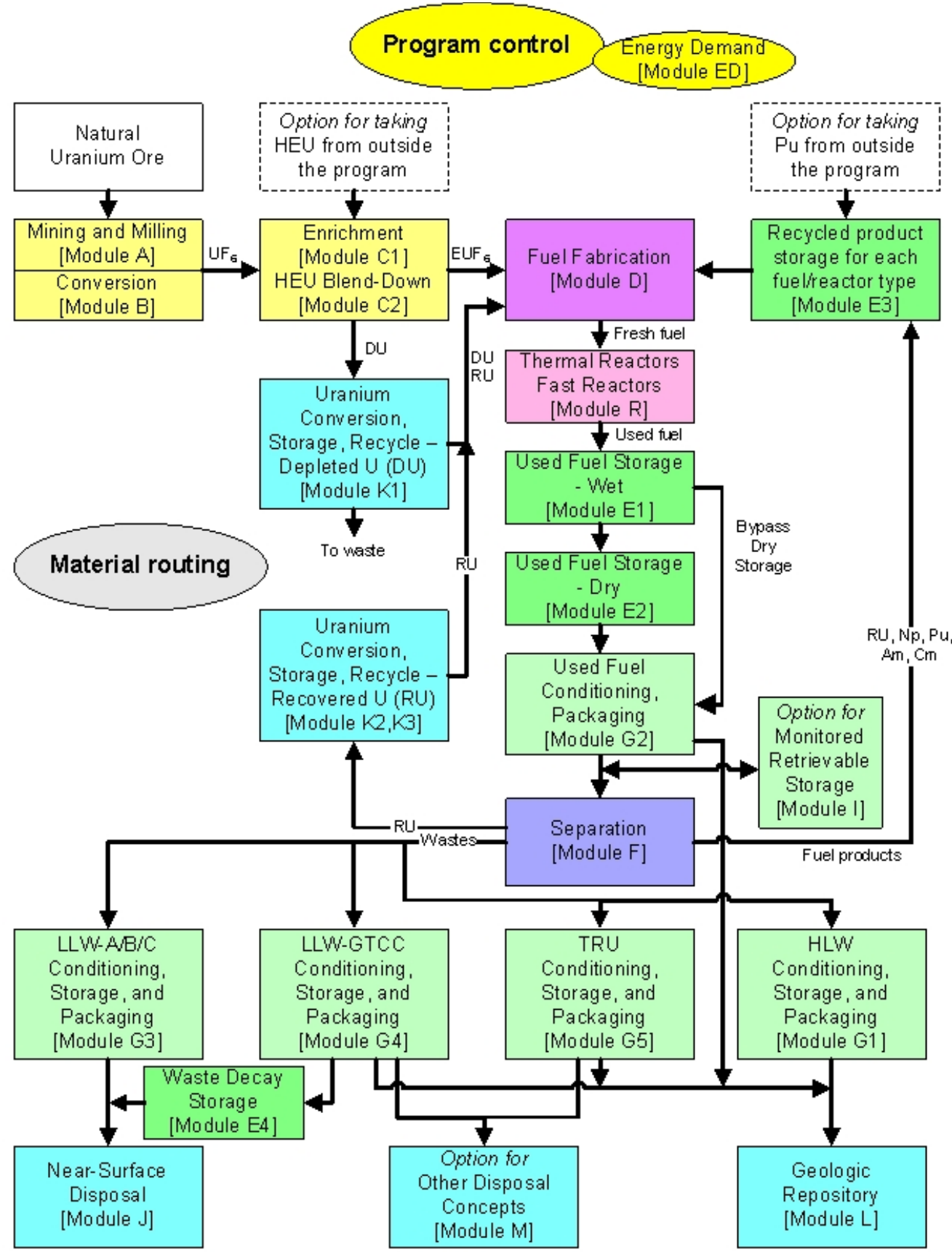

Transportation for High-Level Radioactive Materials (Used fuel, HLW, TRU, LLW-GTCC, recycled fuel) [Module 01]

Transportation for Low-Level Radioactive Materials (LLW-A/B/C, uranium fuel, RU, DU, EU) [Module O2]

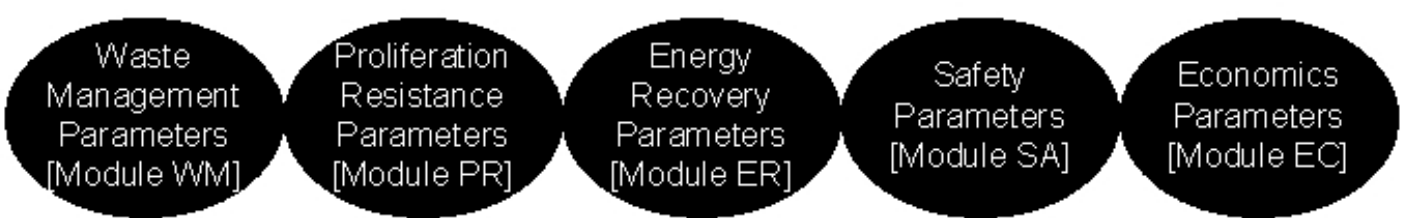

Figure 1-9. Full module structure. 


\subsection{Candidate Fuel Cycles Considered}

In 2011, the FCT program started tests of a formal screening process.[ISEP2011, Hardin2010] Although not definitive, that effort provides guidance to this study with regard to the range of options for which we may wish to have tools and data. Table 1-5 lists relevant candidates (whether from the screening process or not) and distinctive features from the standpoint of dynamic analyses.

Table 1-5. Candidate Fuel Cycles Considered in this Study.

\begin{tabular}{|c|c|c|c|}
\hline Strategy & $\begin{array}{l}\text { Screening } \\
\text { Designation } \\
\text { [ISEP2011] }\end{array}$ & Case & Distinctive features \\
\hline \multirow{5}{*}{$\begin{array}{l}\text { Once } \\
\text { through } \\
(\mathrm{O}-\mathrm{T})\end{array}$} & - & LWR-UOX & Previously studied in the DSARR study \\
\hline & $\mathrm{O}-\mathrm{T} / 1$ & HWR & $\begin{array}{l}\text { Continuous fueling and de-fueling } \\
\text { Either NU or EU fueled. }\end{array}$ \\
\hline & $\mathrm{O}-\mathrm{T} / 5$ & Breed \& burn & Very long fuel residence times \\
\hline & $\mathrm{O}-\mathrm{T} / 9$ & MSR breed and discard & $\begin{array}{l}\text { Mix of continuous and discrete fueling; mix of } \\
\text { continuous and discrete de-fueling }\end{array}$ \\
\hline & $\mathrm{O}-\mathrm{T} / 20$ & $\begin{array}{l}\text { FFH breed, shuffle, } \\
\text { discard }\end{array}$ & Externally driven system/fission-fusion hybrid \\
\hline \multirow{4}{*}{$\begin{array}{l}\text { Modified } \\
\text { open } \\
(\mathrm{M}-\mathrm{O})\end{array}$} & $\mathrm{M}-\mathrm{O} / 59$ & $\begin{array}{l}\text { LWR-UOX } \rightarrow \\
\text { HTGR-IMF-TRU }\end{array}$ & Multiple sets of waste management parameters \\
\hline & $\mathrm{M}-\mathrm{O} / 50$ & $\begin{array}{l}\text { LWR-UOX } \rightarrow \\
\text { LWR-IMF-TRU+FP target }\end{array}$ & $\begin{array}{l}\text { Target (heterogeneous reactor) with differential } \\
\text { residence times }\end{array}$ \\
\hline & none & $\begin{array}{l}\text { LWR-UOX } \rightarrow \\
\text { LWR-IMF-Pu+MA target }\end{array}$ & $\begin{array}{l}\text { Target (heterogeneous reactor) with differential } \\
\text { residence times }\end{array}$ \\
\hline & $\mathrm{M}-\mathrm{O} / 50$ & $\begin{array}{l}\text { LWR-UOX } \rightarrow \\
\text { ADS }\end{array}$ & $\begin{array}{l}\text { Externally driven system(EDS)/accelerator } \\
\text { driven systems (ADS)/fission-fusion hybrid }\end{array}$ \\
\hline \multirow{6}{*}{$\begin{array}{l}\text { Full } \\
\text { recycle } \\
(\mathrm{F}-\mathrm{R})\end{array}$} & $\mathrm{F}-\mathrm{R} / 3,60$ & $\begin{array}{l}\text { LWR-UOX } \rightarrow \\
\text { FR (burners) }\end{array}$ & Previously studied in the DSARR study \\
\hline & none & $\begin{array}{l}\text { LWR-UOX } \rightarrow \\
\text { FR (breeders) }\end{array}$ & Totally displace LWR \\
\hline & $\mathrm{F}-\mathrm{R} / 14$ & $\begin{array}{l}\text { LWR-UOX } \rightarrow \\
\text { LWR-MOX-TRU }\end{array}$ & \\
\hline & $\mathrm{F}-\mathrm{R} / 111$ & $\begin{array}{l}\text { LWR-UOX } \rightarrow \\
\text { LWR-MOX } \rightarrow \\
\text { FR }\end{array}$ & Previously studied in the DSARR study \\
\hline & none & $\begin{array}{l}\text { LWR-UOX } \rightarrow \\
\text { LWR-heterogeneous IMF }\end{array}$ & Heterogeneous system, uranium usage \\
\hline & none & MSR & $\begin{array}{l}\text { Mix of continuous and discrete fueling; mix of } \\
\text { continuous and discrete de-fueling }\end{array}$ \\
\hline
\end{tabular}

From a tool development standpoint, the three rows shaded in green are the baseline; they were studied in detail in the DSARR study. Thus, the tools and data were made adequate at the time for the questions posed by management at the time. The distinctive features are those for which other options differ from these "baseline" options and are therefore features for which the existing version of VISION could require modifications to model. 


\section{VISION IS THE CURRENT TOOL}

This chapter focuses on the key tool for dynamic analyses, VISION. It is limited to what information can be calculated, not on how the information can best be presented, e.g., new and improved ways to visualize the impact of adopting various fuel cycles.

The chapter starts with the current capabilities of the model and the current types of outputs. The former are those things that enable or constrain what types of fuel cycles the model can actually calculate. The latter denotes the performance parameters that are currently calculated. As an example of the latter, a University of Wisconsin student, Tracy Radel, made a performance-related VISION sub-model that estimated (using Argonne National Laboratory (ANL) calculations) the heat impact of different waste streams on a Yucca Mountain-type geologic repository. Re-adding that to the current VISION model would not be a change to the fuel cycle capabilities but would enable a new performance output. Starting with Section 2.3, the chapter addresses the areas of $\mathrm{Th} / 233$, waste management, routing, physics, economics, validation and verification, and other possibilities.

\subsection{Current Fuel Cycle Capabilities}

Per the VISION user guide,[Jacobson2011] VISION 3.4 can model almost any fuel cycle's reactor, fuel type, and separation type, with the following major exceptions:

- Fuel cycles constrained by thorium resources or U233 content in fuels. VISION includes U233 and thorium isotopes, but assumes fuel availability is constrained by the supply of enriched uranium or one or more TRU isotopes. See Section 2.3.

- Fuel cycles in which the supply of fuel depends on some other technology that you wish to include in the model, e.g., externally-driven accelerators or fission-fusion hybrids as a source of neutrons and/or nuclear fuel. This is addressed in Section 2.6.3.

- Fuel cycles that have greater than two reactors but require that two types of reactors to be in some fixed proportion or some constraint that only applies to two reactor types. VISION can constrain the sum of all reactor types to meet some total electricity level or constrain each reactor type separately. It cannot do a case in-between in which a subset of reactor types has one constraint while the remaining reactor types have another. This is relevant to "targets", Section 2.5.1.

- Arrangements in which the used fuel from a given reactor type goes to more than one separation plant, e.g., $30 \%$ to plant 1 and $70 \%$ to plant 2 . VISION is separation-centric in the sense that fuel is "pulled" into separation plants from reactors in the priority that a user specifies rather than "pushed" from reactors to multiple candidate separation plants. See Sections 2.5.2 and 2.5.3.

- Arrangements in which one fuel supplier of a given type of fuel is used preferentially versus another. VISION is separation-centric in that fuel material is "pushed" from separation plants to one or more "buffer boxes" from which fuels are made. Fuel fabrication buffers do not "pull" fuel from separation plants. See Sections 2.5.2 and 2.5.3.

- Arrangements in which specific uranium mines or enrichment plants are to be modeled. Uranium and separative work units (SWUs) are considered commodities and are not modeled at the level of individual facilities nor considered constraints. See Section 2.9.

Table 2-1 summarizes VISION fuel cycle capabilities from the standpoint of which modules are not included, commodities, or facilities. Each column should be read has having the capabilities of the columns to its left. That is, constraints and inputs accumulate as one moves to the right. 
Table 2-1. VISION Fuel Cycle Capabilities.

\begin{tabular}{|c|c|c|c|c|c|}
\hline & $\begin{array}{c}\text { Not } \\
\text { included }\end{array}$ & $\begin{array}{c}\text { Unconstrained } \\
\text { commodities }\end{array}$ & $\begin{array}{c}\text { Constrained } \\
\text { commodities }\end{array}$ & $\begin{array}{c}\text { Single } \\
\text { Facilities } \\
\end{array}$ & $\begin{array}{c}\text { Multiple } \\
\text { Facilities (c) }\end{array}$ \\
\hline $\begin{array}{l}\text { Portions of } \\
\text { fuel cycle }\end{array}$ & $\begin{array}{l}\text { External } \\
\text { supply of } \\
\text { U233, } \\
\text { HEU or } \\
\text { TRU (a) }\end{array}$ & $\begin{array}{l}\text { - Waste } \\
\text { packaging } \\
\text { - LLW-A/B/C } \\
\text { storage } \\
\text { - LLW-GTCC } \\
\text { storage } \\
\text { - Decay storage } \\
\text { - TRU waste } \\
\end{array}$ & $\begin{array}{l}\text { - Uranium ore } \\
\text { - Uranium } \\
\text { enrichment } \\
\text { - (b) }\end{array}$ & $\begin{array}{l}\text { - Repository } \\
\text { - MRS }\end{array}$ & $\begin{array}{l}\text { - Reactor type } \\
\text { - Separation } \\
\text { type } \\
\text { - Fuel } \\
\text { fabrication } \\
\text { type }\end{array}$ \\
\hline $\begin{array}{l}\text { Types of } \\
\text { constraints } \\
\text { (cumulative } \\
\text { moving to } \\
\text { right) }\end{array}$ & & & $\begin{array}{l}\text { - Supply } \\
\text { inventory } \\
\text { - Supply rate }\end{array}$ & $\begin{array}{l}\text { - When } \\
\text { technology } \\
\text { available } \\
\text { - Constraints } \\
\text { during early } \\
\text { deployment } \\
\text { - Time lags for } \\
\text { construction } \\
\text { and licensing } \\
\text { - Build size } \\
\text { (capacity) } \\
\text { - Receipt rate } \\
\text { - Inventory limit }\end{array}$ & $\begin{array}{l}\text { - Availability of } \\
\text { U235 or one } \\
\text { or more TRU. } \\
\text { (U233 control } \\
\text { not an option.) } \\
\text { One or more of } \\
\text { the following } \\
\text { - Input push } \\
\text { - Input pull } \\
\text { - Output push } \\
\text { - Output pull }\end{array}$ \\
\hline $\begin{array}{l}\text { Types of } \\
\text { performance } \\
\text { input } \\
\text { variables } \\
\text { (cumulative } \\
\text { moving to } \\
\text { right) }\end{array}$ & & $\begin{array}{l}\text { - Wasteform } \\
\text { mass per waste } \\
\text { (waste loading) } \\
\text { - Wasteform } \\
\text { volume per } \\
\text { wasteform } \\
\text { mass } \\
\text { (wasteform } \\
\text { density) } \\
\end{array}$ & & - Lifetime & $\begin{array}{l}\text { - Input/output } \\
\text { recipe by fuel } \\
\text { type } \\
\text { - Separation } \\
\text { performance } \\
\text { by separation } \\
\text { type }\end{array}$ \\
\hline $\begin{array}{l}\text { Analysis of } \\
\text { transitions }\end{array}$ & & & & $\begin{array}{l}\text { - Routing, fuel } \\
\text { type, sep } \\
\text { performance by } \\
\text { year } \\
\text { - Repository and } \\
\text { MRS receipt } \\
\text { rate and/or } \\
\text { inventory limit } \\
\text { by year }\end{array}$ & $\begin{array}{l}\text { Routing, fuel } \\
\text { type, separation } \\
\text { performance by } \\
\text { facility by year }\end{array}$ \\
\hline \multicolumn{6}{|c|}{$\begin{array}{l}\text { a. The option of (time-dependent) external supply of HEU (for downblending), U233, or TRU is not } \\
\text { included. Such supplies could be stockpiles from weapon dismantlement or an externally-driven } \\
\text { source such as fission-fusion hybrids used for fuel breeding. } \\
\text { b. Thorium/U233 is not included as fuel cycle option, although the individual isotopes are. } \\
\text { c. Individual plants are not modeled, but rather facility types - up to } 10 \text { reactor types, } 10 \text { separation } \\
\text { types, } 10 \text { fabrication types. }\end{array}$} \\
\hline
\end{tabular}


Thus, if FCT program needs to analyze a function as a facility that is currently a commodity, a model change would be required. For example, uranium mining, conversion, and enrichment are commodities, bought on the open market. The model calculates how much of each is needed and they are assumed unlimited in supply. If instead one wanted to include the constraints that new uranium mines require time to find, time to license, and time to bring to full production, uranium mining would have to be changed from a commodity approach to a facility approach, and relevant input data sought from users.

\subsection{Current Performance Outputs}

VISION models all the mass flows denoted in Chapter 1 and does so at the level of individual isotopes, individual elements, and groups of elements as explained in Section 2.6. In particular, all the fuel isotopes important to long-term waste management are included.[Piet2009] So, even if a particular performance output is not currently in the model (Table 2-2), it would generally be straightforward to add others as long as they can be based on the mass and information flows already in the model.

Table 2-2. VISION Performance Outputs.

\begin{tabular}{|l|l|}
\hline Uranium & $\begin{array}{l}\text { Separative work units } \\
\text { Consumed uranium ore } \\
\text { Consumed uranium } \\
\text { Depleted uranium } \\
\text { Enrichment rate }\end{array}$ \\
\hline $\begin{array}{l}\text { Fuel } \\
\text { fabrication }\end{array}$ & $\begin{array}{l}\text { \# of facilities in design \& licensing, construction, ready, operation, near retirement, retired } \\
\text { Mass in fuel fabrication buffers (available to be made into fuel) }\end{array}$ \\
\hline Reactors & $\begin{array}{l}\text { \# of reactors in construction, ready, operation, near retirement, near shutdown, retired } \\
\text { Electricity generated per year by reactor type } \\
\text { Reactor capacity by reactor type } \\
\text { Reactors/year beginning operation, retiring } \\
\text { Reactor capacity/year added or retired }\end{array}$ \\
\hline Overall & $\begin{array}{l}\text { Mass (total and by element) by reactor type in U conversion, U enrichment, fuel } \\
\text { fabrication, ready fuel, fuel in reactor, fuel in wet storage, fuel in dry storage, fuel in MRS, } \\
\text { Mass/year of fuel charged and discharged }\end{array}$ \\
\hline Separation & $\begin{array}{l}\text { \# of facilities in design \& licensing, construction, ready, operation, near retirement, retired } \\
\text { Separation capacity } \\
\text { Mass/year into separation }\end{array}$ \\
\hline Waste & $\begin{array}{l}\text { Waste mass, Mass of waste form, volume of waste form by waste stream (iodine, inert gas, } \\
\text { etc.) } \\
\text { Packaged volume of used fuel } \\
\text { Heat rate, long-term heat commitment, long-term dose, radiotoxicity in fuel fabrication, } \\
\text { ready fuel, fuel in reactor, wet storage, dry storage, MRS, separations, separated material } \\
\text { buffer box, LLW class A/B/C, LLW GTCC, decay storage, TRU waste, HLW, Retrievable } \\
\text { repository, permanent repository, depleted uranium }\end{array}$ \\
\hline
\end{tabular}

Note the following definitions:

- Waste mass = the mass of initial-heavy-metal in a waste stream

- Waste form mass = waste mass $\mathrm{x}$ the waste loading (waste form mass/waste form) necessary to stabilize the waste in the selected waste form

- Waste form volume = waste form mass $\mathrm{x}$ waste form density (volume/mass) for that waste form

- $\quad$ Packaged volume $=$ waste form volume $\mathrm{x}$ packing - not yet implemented in VISION 


\subsection{Missing Category of Fuel Cycles - Thorium/U233}

All actinide isotopes with halflives over 0.5 years are already tracked by VISION, including Th228 to Th232 (except Th231) and U232 to U238 (except U237). But, to analyze Th/U233 fuel cycles two additional changes would be needed.

The first is that the use of Th ore (Th232) is not tracked, as is the use of uranium ore. Unlike uranium, thorium is not, and cannot be, enriched. So, it is a simple matter of adding a thorium inventory counter as thorium is used as feedstock. But, then there would eventually have to be input/output changes for information management.

The second change is to enable appropriate "flow controls". The current model allows the user to specify for a given reactor the flow control, i.e., what is the rate limiting group of isotopes that the model uses to know how much fuel can be made given available inventory. Exception: if the fuel is enriched or natural uranium, the supply of fuel is considered unlimited and there is no need for flow control. Instead, the model simply calculates how much EU or NU is required.

The existing options are all-TRU, all-Pu, Pu239, Pu240, Pu241, or the minimum (most restrictive) of $\mathrm{Pu} 239 / 240 / 241$. For example, with all-Pu, the model determines from the fuel recipe (selected by year) the value of mass-Pu/mass-heavy-metal in fuel. Then, the amount of fuel that can be made in the next time step is the mass of $\mathrm{Pu}$ available divided by mass-Pu/mass-heavy-metal-fuel. All-TRU is typically used for fast reactors. All-Pu is typically used for thermal reactors.

So, depending on what part of $\mathrm{Th} / \mathrm{U} 233$ option space is to be analyzed, one might need to create flow controls such as the following

$\mathrm{U} 233$

$\mathrm{U} 233+\mathrm{U} 235$

$\mathrm{U} 233+\mathrm{Pu} 239$

$\mathrm{U} 233+\mathrm{TRU}$

Any isotope or combinations of isotopes that are deemed potentially rate controlling in making fuel have to be available as flow controls. This is relatively straightforward but tedious as many variables in the model would have to be changed.

There are two subtle points. First, the current model requires a selection of a single flow control option for a reactor type. It is not connected directly to fuel type. This is adequate for the U/Pu/TRU option space. A given reactor either depends on U235 (in which flow control is not required), Pu (thermal), or TRU (fast). Th/U233 option space is at least as broad as U/Pu239 option space. One would have to determine if a single flow control option would be adequate to cover the range of fuels envisioned for each reactor type. A simple U233 flow control option would probably not be sufficient. One would need other options such as perhaps $\mathrm{U} 233+\mathrm{Pu} 239$, so that the model would allow fuel to be made on the basis of the sum of those isotopes in each time step. Or, one could have an adjusted sum such as $\mathrm{a}(\mathrm{U} 233)+\mathrm{b}(\mathrm{Pu} 239)$ so that $\mathrm{U} 233$ and Pu239 would be weighted differently. If such combination options were not adequate, the alternative would be to change the model so that flow control depended on fueltype, not reactor. We have not found any such situations, but also have not thought through all of $\mathrm{Th} / \mathrm{U} 233$ option space.

The second subtle point is the concept of "contingent fuel." For each fuel recipe, the user can specify if there is a fuel the model should use if the chosen fuel is unavailable. For example, one can model fast reactors in two ways - allow or not allow the model to use enriched uranium to fuel a fast reactor if TRUbased fuel is unavailable. There is no option of double contingent fuel, i.e., if fuel X can't be made, use fuel Y; if fuel Y can't be made, make Z. To date, we have not found a need for double contingent fuel. Instead, for scenarios analogous to the Indian national scenario (LWR-UOX, put TRU into LWR with Th 
as fertile component, put resulting U233 into LWR), use the multiple recycle pass feature to capture the evolution of the fuel composition. In this example, pass $0=$ LWR UOX, pass $1=$ LWR TRU-Th, pass 2 $=$ LWR U233-Th.

\subsection{Likely Need More Waste Management}

Although VISION has more waste management details and outputs than any model we know of, there are three areas in which we can see the need for more work - co-flows, constraints on waste loading or wasteform density, and automatic waste classification.

\subsubsection{Co-flows}

The mass flows in VISION, and other models to our knowledge, are the fuel isotopes and the transmutation and fission products that arise from them. Other materials co-flow with the fuel isotopes during reprocessing. These co-flow materials can be:

- Components of the fuel matrix, cladding, or assemblies (e.g., Zircaloy, steel, or $\mathrm{C} / \mathrm{Si} / \mathrm{C}$ cladding, oxygen, carbon, or zirconium as a matrix material, steel fuel assembly structure, or $\mathrm{LiF}^{-\mathrm{BeF}_{2}}$ salt)

- Separations plant process materials and equipment (e.g., filters and spent equipment) and reagents (e.g., inorganic and organic solvents)

- Recycle fuel fabrication plant and process materials (e.g., filters, spent equipment, and crucibles)

- Waste treatment plant and process materials (e.g., filters, waste form additives, and spent equipment).

For example, in LWR fuel assemblies, there is $\sim 0.25 \mathrm{~kg}$ of Zircaloy and $0.06 \mathrm{~kg}$ stainless steel per $\mathrm{kg}$ fuel.

The current version of VISION allows 6 co-flows. The first five materials, Zr, stainless steel, process discard, salts and metals, require the user to specify the number of kilograms of material per kilogram of fuel. The sixth material, Rags and Bags, requires the user to specify the volume (in cubic meters) per kilogram of fuel. These materials are part of the fuel cycle, but are not active parts of the fuel. They are important however for waste, storage, and economic purposes.

The values for these co-flow streams are currently approximations. The actual types and amounts of these co-flows can vary for different fuel cycle and reprocessing cases. Metal fuel assemblies for fast reactors contain much more steel than do LWR UOX fuel assemblies. Silicon carbide and graphite in used pebble bed or prismatic fuels replace the metal cladding and assembly structures of LWRs and FR fuels. Different separation processes, and even different types of aqueous separations processes, will result in different amounts of different types of spent reagents, filters, and equipment. And, different assumed waste forms can vary in waste loading and the amounts and types of additives used in combination with the waste streams to produce the desired waste forms with the necessary durability.

Any user who is interested in the relevance of the values for these co-flows should review these values and determine if they should be revised, and the model modified, to better reflect his application. Several studies in the past decade provide the most up-to-date estimates for co-flows, waste loadings, and waste forms, which a user may refer to. Recent references in the public domain that users may refer to include [Gombert2008], [Bays2010], [Soelberg2010], [Carter2011], [Jones2011], and [Piet2011b]. The user should be warned that these references contain sometimes dissimilar information because of different assumptions made by those authors. Discrepancies between estimates of masses and volumes of waste streams and waste forms will continue to persist as long as there are uncertainties in the performance and operation of separations and fuel fabrication processes, and disagreements continue in how conservatively those uncertainties are addressed. 
Unfortunately, VISION currently does little with co-flow materials. It would be straightforward to expand the above list of co-flow materials and connect the co-flows to waste disposition, similar to what has already been done in some of the above references.

\subsubsection{Constraints on waste loading or wasteform density}

The current model calculates waste form masses and waste form volumes based on waste streams and fixed coefficients denoting waste loading and wasteform density. For a first approximation and when the composition of an individual waste stream is fairly constant, this is adequate.

If, however, a waste stream would see large variations in composition, it would be appropriate to add submodels that calculate waste loading and/or wasteform density on the basis of the composition of the waste stream. Example 1: the reason the mass of Mo-Rh-Ru-Pd is tracked separate from other transition metals is that noble metals, which include these elements in used fuel, are known to affect waste loading in the waste glass form. That is, these elements' solubility in glass is limited and so the waste loading could be changed from a constant to an expression based on the amount of these elements in waste, when it is known that the glass waste loading is limited by the amount of these elements in the waste stream. However, it is not this simple, because the glass waste loading could also be limited by many other parameters including the decay heat, lanthanides, alkali/alkali earth elements, zirconium, halides, and actinides. VISION already calculates heat of waste streams and so it would be straightforward to add a sub-model calculating waste loading and/or wasteform density based on heat.

Indeed, the complementary FIT model has a sub-model on glass waste form, provided by Joe Ryan of the separation and waste form campaign.[Piet2011b] This sub-model accounts for all of the above-listed parameters, determines which parameter(s) limit the waste loading for a given type of glass, and determines the maximum waste loading. However, new waste form research and development continues. In particular, advances are being made in glass types such as iron phosphate glasses that can tolerate higher levels of halides and sulfate, and glass-ceramics that can tolerate higher decay heat levels and actinides.

\subsubsection{Automatic waste classification}

The current model assigns each waste stream to be one of the following based on a time-independent user decision.

- $\mathrm{LLW}-\mathrm{A} / \mathrm{B} / \mathrm{C}$

- $\quad$ LLW-GTCC

- Decay storage

- $\quad$ TRU waste

- HLW

This is fine for most waste streams that change little, and for which waste classification is not particularly unclear based on current nuclear waste regulations. However, there are some circumstances where classifying some waste streams is not immediately clear. First, current regulations in the U.S. do not specifically account for the variety of waste streams separated during used fuel reprocessing, and in the cases of some waste streams, regulatory interpretation is not clear.[Bays2010] Some debate has continued for years about how some waste streams separated during used fuel reprocessing, such as cladding and isotopes such as tritium and krypton-85, should be classified.

Second, the waste classification may change if the composition of the waste stream, or the wasteform or waste loading, changes. This could be especially true for low level waste streams that are thermally treated to volume-reduce the otherwise relatively large-volume (but low activity) waste streams. The act of volume reduction could increase the classification from Class C or lower, to GTCC. 
Third, we should expect that, if used fuel reprocessing is accepted and implemented, then the currently source-based waste regulations would likely be revised to better regulate the variety of potential waste streams and ensure environmental and public protection. Considering this potential, it is not unreasonable to describe and classify waste streams when analyzing future fuel cycle scenarios according to their risk instead of their source.

So if simulations for a given analysis are to compare or examine wide ranges of separations or waste stream/wasteform options, then an automatic waste classification routine should be added. For example, if one wanted to start separations with all fission products going to HLW but later transition to a strategy in which some fission products were separated into LLW-A/B/C (low heat, low duration), LLW-GTCC (low heat, long duration), decay storage (high heat, low duration), and HLW (high heat, high duration), one needs a routine in which the user would define the waste classification rules and VISION would classify waste accordingly.

\subsection{Likely Need More Grouping and Routing Options}

The previous parts of Chapter 5 mostly address technologies apart from each other. This subsection addresses ways that technologies interact with each other.

- Grouping of "reactor" types for simulations of heterogeneous cores.

- Routing options among reactors, separation, and fuel fabrication.

\subsubsection{Grouping to enable targets}

The current VISION model allows users to specify how reactor type growth is to be calculated:

1. Force VISION to use the number of reactors input by the user on the Reactor \#'s worksheet. The nuclear power growth specifications are ignored. Reactors are built whether there is fuel or not. Reactors can only begin operation if there is the specified fuel.

2. Let system optimize reactor mix using the percent goals set on Reactor \%s worksheet times the nuclear power growth specified on Growth Rate. That is, the user specifies growth for the entire fleet and the reactor- $\%$ inputs allow the user to specify the market share to be allocated among reactor types. If fuel is unavailable for reactor type $\mathrm{N}$, it builds reactor type $\mathrm{N}-1$.

3. Force VISION to build reactors to match the user specified growth for each reactor type via the end-simulation value on Reactor Facility worksheet times the year by year fraction of that value on Reactor Growth \% of Final worksheet. This is similar to the first, except the growth goals are specified for each reactor type independently.

The second and third options combine all or none of the reactor types together. There is no in-between option in which a subset of reactor types would be tied together.

Now, consider "target" options, in which some of the reactor core is one type of fuel and the rest of the core is either another fuel or a net neutron-absorbing target. Examples include a driver core with Pu fuel and targets of minor actinides. There are two ways these can be modeled.

The first is currently used for breeder cases, heterogeneous IMF (mixture of UOX pins and IMF pins in each assembly). Use a homogenized input and output fuel composition. All of the homogenized fuel enters and leaves the core at the same time. This is quite appropriate for heterogeneous IMF because the pin mixtures are present in each fuel assembly. It may be inappropriate for breeder cases.

The second would be to model the arrangement by assigning one reactor type to the driver core and another reactor type to the target. This allows the two to have separate compositions, burnup, fuel residence time, and flow control. The problem is that the amount of the two reactor types during the simulation would not be coupled. Indeed, sometimes one would not want to strictly couple as one 
approach to "targets" is to use targets in reactors only if the minor actinides supply warrants but use the normal fuel otherwise. But, if one wants to tie the two reactor types together, the only current methods are to use options 2 and 3 above: manually tell the model how many of each reactor type or tell the model the nuclear electricity goal separately for each reactor type.

More complex arrangements would require a model change.

\subsubsection{Routing Push and Pull}

Reconsider Figure 1-2. As fuel moves through the fuel cycle, there are two primary functions transformation and routing. Transformation occurs at facilities and routing occurs between facilities. Routing does not change the material, it merely moves mass from one place to another. In the parlance of system dynamics, types of facilities are inventories or stocks; routing are flows. Facilities transform material in various ways, e.g.

- Transmutation at reactors,

- Separation (or partition) at separation plants,

- Fabrication at fabrication plants,

- Waste form creation and waste form packaging at waste processing plants, and

- Isotopic decay at waste storage and all of the above. ${ }^{c}$

Generally, the performance of each transformation operation is under the user's control. Transformation occurs by user-selected "recipes" that translate an input composition to an output composition.

Separation occurs by user-selected "separation efficiency matrices" that partition incoming used fuel into fuel products, recovered uranium, and waste streams. At present, fabrication is not user controlled, material sent to a given fabrication plant always undergoes the type of fabrication appropriate for associated reactor type's fuel, which is itself specified by the fuel recipe selected for that reactor. That is, there is a 1:1 correspondence between fuel fabrication plant types and reactor types.

Routing is also generally under the user's control. The primary exception is again fuel fabrication to reactor. There is no provision to route fuel from one fabrication plant type to a different reactor type.

In principle, routing can be specified either by "pushing" or "pulling."

- Push - Material is sent by a facility independent of whether the receiving facility has requested the material. Typically, there must be a buffer inventory at the receiving facility. Example: Wet fuel storage ejects used fuel to dry fuel storage at the end of its wet fuel storage time.

- Pull - A receiving facility attempts to pull (requests) material from a designated set of sending facilities. Thus, there must be a buffer inventory at each sending facility because the material may or may not be requested by one or more receiving facilities. Example: Recycling request used fuel from dry fuel storage when there is available capacity. Dry fuel storage holds the material until it is requested downstream.

A real fuel cycle system could have both push and pull routing and thus buffers at both sending and receiving facilities. In VISION 3.4, we have chosen to model routing from reactors to separation as "pull", hence buffers are closely associated with reactors, i.e., where used fuel is located such as wet and dry storage. That is, used fuel stays in used fuel storage unless or until pulled by separations or pulled by waste disposal. The routing of separation to fabrication/reactors is primarily modeled as "push", i.e., buffers are envisioned at receiving fuel fabrication plants. Whether push or pull, routing can theoretically be controlled either by priority order or percentage. Priority order means that some capacity is used by a

c. Exception - Isotopes are not decayed once put into a repository as our primary waste management concern is estimating the amount and character of waste forms at the time of emplacement. 
set of incoming flows such that source one is used first, then source two, etc. until the full capacity of the facility type is used. VISION models reactor-to-separation as push/priority-list. Percentage means that material is received or sent to a set of places allocated by percentages. VISION models separation-tofabrication/reactor by pull/percent.

Figure 2-1 shows the routing approach in VISION as well as two of the many alternatives to help differentiate among options. As noted above, VISION uses pull/priority routing from reactors to separation plants and push/percent from separation plants to fuel fabrication (hence reactors). The first alternative shown is pull/priority (reactor to separation) then pull/percent (separation to fuel fabrication). The second alternative is push/percent for both reactor-separation and separation-reactor. All options require at least one buffer between reactor and separation and one between separation and fuel fabrication; the diagram shows the buffer shifting position. (Here, "position" means in a logical sense, the physical location of buffers is not addressed.)

If other routing arrangements are desired, a difficult model change would be required. 


\section{VISION routing approach}

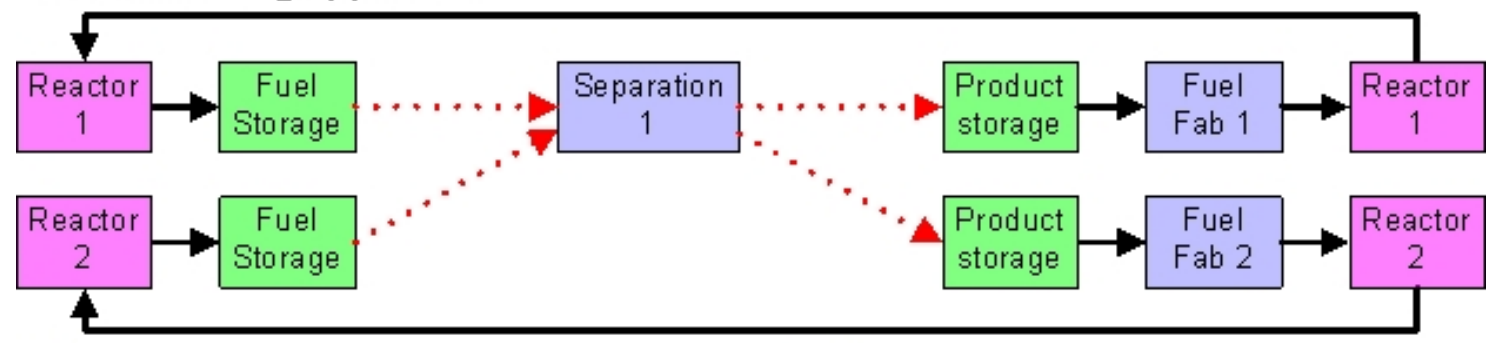

Pull from storage buffer to fill Separation capacity. Separation 1 pulls first, then 2, etc. Fuel stays in storage until pulled.

Priority order - reactor $1 /$ pass 0 , then reactor 2 /pass 0 , etc.
Push from Separation into one product storage for each Fuel Fab. Products pushed whether Fuel Fab ready to use or not.

Percent allocation $-X \%$ to Fuel Fab 1, Y \% to Fuel Fab 2, etc.

\section{Alternative routing approach}

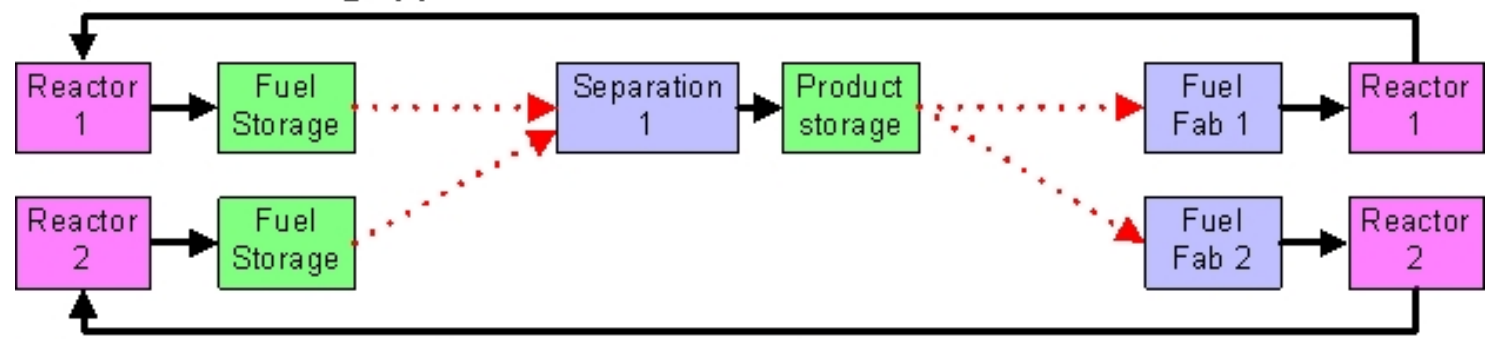

Pull from storage buffer to fill

Separation capacity. Separation 1 pulls first, then 2, etc. Fuel stays in storage until pulled.

Priority order - reactor $1 /$ pass 0 , then reactor 2 /pass 0 , etc.
Pull from Separation product storage into Fuel Fab. Fuel Fab 1 pulls first, then 2 , etc.

Products stay until pulled.

Percent allocation - $X \%$ pulled from Sep 1, Y \% from Sep 2, etc.

\section{Alternative routing approach}

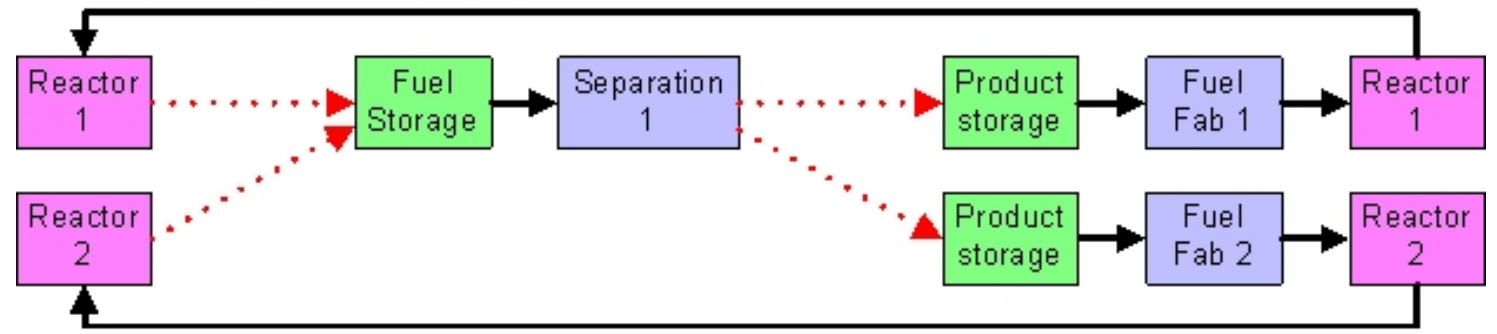

Push from Reactors to incoming

Separation buffers, regardless of

Separation readiness.

Percent allocation - Reactor 1 s ends

$X \%$ to Separation 1, $Y \%$ to Separation

2 , etc, etc. Reactor 2 sends $Z \%$ to

Separation 1, etc.
Push from Separation into one product storage for each Fuel Fab. Products pushed whether Fuel Fab ready to use or not.

Percent allocation $-X \%$ to Fuel Fab 1, Y \% to Fuel Fab 2, etc.

Figure 2-1. Push and pull arrangements. 


\subsubsection{Routing Priority}

Generally, the priority among reactor types, among separation types, and among fuel fabrication types is controlled by the user through various input matrices. For example, by "pushing" fuel products from separation to fuel fabrication (by percent) and the 1:1 correspondence between fuel fabrication and reactor fuel type, there is no additional prioritization required at fuel fabrication. Recycled material has already been allocated by the separation efficiency matrices that push fuel products into each fuel fabrication.

There are four exceptions; these must be considered in deciding how to set up a scenario.

- First, recycling routing matrices define for each separation type the order in which that separation type pulls used fuel, e.g., pull from Fuel type 1, then Fuel type 3, then Fuel type 2. That separation type will pull fuel each time step until its separation capacity is used. If the user allows more than one separation type to pull the same fuel type, then the separation type with the lower number goes first - a hard-wired prioritization not under user control except by the order in which the user defined separation types.

- Example: Separation 2 and 3 are allowed to pull from Fuel type 2, whether or not they pull from other fuel types. So, Separation 2 is allowed to pull from any available Fuel type 2 to use its current separation capacity. After Separation 2 is completed, Separation 3 could use any remaining available fuel type 2. Separation 2 goes before Separation 3.

- Second, legacy reactors retire in the order reactor-1 first, then reactor-2, and so forth.

- Third, if the model cannot order as many of reactor-N as you request via the "\%" market allocation settings, it will build reactor type $\mathrm{N}-1$.

- Fourth used fuel going to a repository will be taken (if the repository is open) from reactor-1 first, reactor-2, and so forth.

\subsection{May Need More Reactor Physics Options}

There are three aspects of reactor physics in dynamic simulations.

The first is how mass is divided into isotopes.

The second is what goes in and out of reactors. The "isotope" question impacts the structure of the entire model, whereas the in/out of reactors is only structurally connected to the reactor modules.

The third is the possibility of externally-driven fuel supply or waste transformation. By "external" we mean sources and sinks other than fission reactors.

\subsubsection{Isotopes}

Reactor physics models track over a thousand isotopes. However, outside of reactor modules, one does not need to track all of them. Reasons to track isotopes include the following:

1. Isotopes important to fuel value, including fuel and key neutron absorbers

2. Isotopes impacting the chemistry of fuel cycle facilities

3. Isotopes impacting waste management burdens

4. Isotopes impacting waste management operations.

The first and third of the above list require tracking individual isotopes such as Pu239 or Tc99. The second and fourth only require tracking chemical elements, differentiation among the isotopes of the same chemical element is not required and would only add excessive detail. For example, Mo constrains waste glass formation, but individually tracking the 7 stable Mo isotopes and the various radioactive Mo isotopes is not needed. 
In some cases, tracking individual elements is not needed, only groups of chemical elements.

So, models tend to track a mix of individual isotopes, individual elements, and groups of elements.

Figure 2-2 shows the grouping of elements in VISION. For example, the halogens are tracked by I-129 and then all other halogen mass grouped together. Based on this grouping, Table 2-3 shows the isotopes, elements, and groups of elements in VISION.

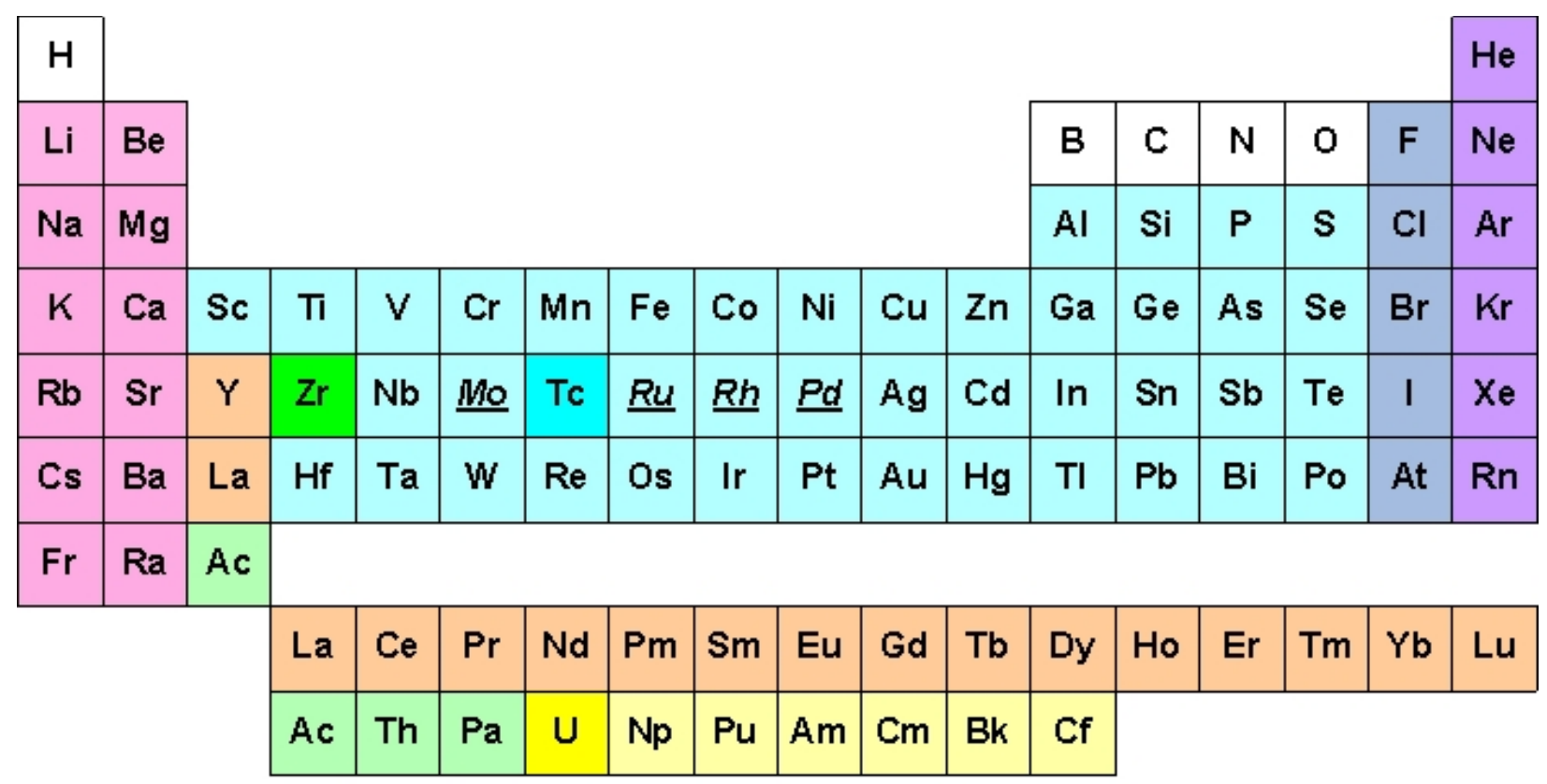

\begin{tabular}{|l|}
\hline $\begin{array}{l}M o \\
\text { in glass }\end{array}$ \\
\hline $\begin{array}{l}\text { The other transition metals of significance } \\
\text { are } \mathrm{Se}, \mathrm{Cd}, \mathrm{Sn}, \mathrm{Sb}\end{array}$ \\
\hline Lanthanides $+\mathrm{Y}$ tracked separately \\
\hline $\begin{array}{l}\mathrm{Ac}, \mathrm{Th}, \mathrm{Pa} \text { are important actinide decay } \\
\text { chain elements }\end{array}$ \\
\hline In UREX+, U is removed separately \\
\hline TRU elements \\
\hline
\end{tabular}

\begin{tabular}{l}
$\mathrm{H} 3$ and $\mathrm{C} 14$ are tracked separately \\
\hline $\begin{array}{l}\text { The only Group 1A/2A elements of } \\
\text { significance are } \mathrm{Rb}, \mathrm{Sr}, \mathrm{Cs}, \mathrm{Ba}\end{array}$ \\
\hline $\begin{array}{l}\text { The only Halogens of significance are } \mathrm{Br} \\
\text { and I }\end{array}$ \\
\hline $\begin{array}{l}\text { The only inert gases of significance are } \\
\mathrm{Kr} \text { and Xe }\end{array}$ \\
\hline In UREX+, Tc is removed separately. \\
\hline $\begin{array}{l}\text { Zr is tracked separately because its mass } \\
\text { is dominated by cladding, not fuel per se }\end{array}$ \\
\hline
\end{tabular}

Figure 2-2. Periodic Table as seen from fuel cycle system analysis perspective.[Piet2009] 
Table 2-3. Tracked Isotopes and Chemical Elements [Piet2009]

\begin{tabular}{|c|c|c|c|}
\hline \multicolumn{2}{|c|}{ Actinides and Decay Chain } & \multicolumn{2}{|c|}{ Fission Products } \\
\hline He4 (stable) & & $\mathrm{H} 3$ & \multirow{3}{*}{ Other gases } \\
\hline $\mathrm{Pb} 206$ & \multirow{5}{*}{ Transition metals } & C14 & \\
\hline $\mathrm{Pb} 207$ & & C-other & \\
\hline $\mathrm{Pb} 208$ & & Kr81 & \multirow{3}{*}{$\begin{array}{l}\text { Inert gases } \\
\text { (Group 0) }\end{array}$} \\
\hline $\mathrm{Pb} 210$ & & Kr85 & \\
\hline Bi209 & & Inert gas other $(\mathrm{Kr}, \mathrm{Xe})$ & \\
\hline $\mathrm{Ra} 226$ & \multirow{2}{*}{ Group 2A } & $\mathrm{Rb}$ & \multirow{3}{*}{ Group $1 \mathrm{~A} / 2 \mathrm{~A}$} \\
\hline Ra228 & & Sr90 w/Y90 decay & \\
\hline Ac227 & \multirow{6}{*}{ Actinides } & Sr-other & \\
\hline Th228 & & Zr93 w/Nb93m decay & \multirow{3}{*}{ Zirconium } \\
\hline Th229 & & $\mathrm{Zr95}$ w/Nb95m decay & \\
\hline Th230 & & Zr-other & \\
\hline Th232 & & Tc99 & \multirow{2}{*}{ Technetium } \\
\hline $\mathrm{Pa} 231$ & & Tc-other & \\
\hline $\mathrm{U} 232$ & \multirow{6}{*}{ Uranium } & Ru106 w/Rh106 decay & \multirow{3}{*}{$\begin{array}{l}\text { Transition metals that } \\
\text { constrain glass waste } \\
\text { forms }\end{array}$} \\
\hline U233 & & $\operatorname{Pd} 107$ & \\
\hline U234 & & Mo-Ru-Rh-Pd-other & \\
\hline $\mathrm{U} 235$ & & Se79 & \multirow{5}{*}{ Other transition metals } \\
\hline $\mathrm{U} 236$ & & $\mathrm{Cd} 113 \mathrm{~m}$ & \\
\hline $\mathrm{U} 238$ & & $\mathrm{Sn} 126 \mathrm{w} / \mathrm{Sb} 126 \mathrm{~m} / \mathrm{Sb} 126$ & \\
\hline $\mathrm{Np} 237$ & Neptunium & Sb125 w/Te125m decay & \\
\hline $\mathrm{Pu} 238$ & \multirow{6}{*}{ Plutonium } & TM-other (Co-Se, Nb, Ag-Te) & \\
\hline Pu239 & & I129 & \multirow{2}{*}{$\begin{array}{l}\text { Halogens } \\
\text { (Group 7) }\end{array}$} \\
\hline $\mathrm{Pu} 240$ & & Halogen-other $(\mathrm{Br}, \mathrm{I})$ & \\
\hline $\mathrm{Pu} 241$ & & Cs134 & \multirow{5}{*}{ Group $1 \mathrm{~A} / 2 \mathrm{~A}$} \\
\hline $\mathrm{Pu} 242$ & & Cs135 & \\
\hline $\mathrm{Pu} 244$ & & Cs137 w/Ba137m decay & \\
\hline Am241 & \multirow{3}{*}{ Americium } & Cs-other & \\
\hline Am242m & & $\mathrm{Ba}$ & \\
\hline Am243 & & Ce144 w/Pr144m/Pr144 decay & \multirow{9}{*}{ Lanthanides (plus Y) } \\
\hline $\mathrm{Cm} 242$ & \multirow{8}{*}{ Curium } & Pm147 & \\
\hline $\mathrm{Cm} 243$ & & Sm146 & \\
\hline $\mathrm{Cm} 244$ & & Sm147 & \\
\hline $\mathrm{Cm} 245$ & & Sm151 & \\
\hline $\mathrm{Cm} 246$ & & Eu154 & \\
\hline $\mathrm{Cm} 247$ & & Eu155 & \\
\hline $\mathrm{Cm} 248$ & & Ho166m & \\
\hline $\mathrm{Cm} 250$ & & LA-other plus Yttrium & \\
\hline Bk249 & Berkelium & & \\
\hline Cf249 & \multirow{4}{*}{ Californium } & & \\
\hline $\mathrm{Cf} 250$ & & & \\
\hline Cf251 & & & \\
\hline Cf252 & & & \\
\hline
\end{tabular}


This scheme has proven adequate to date. There are several things this 81 -item arrangement does not allow VISION to do.

- Calculate the accumulation and activation of impurity isotopes and elements. For example Cl36, produced by activation of $\mathrm{Cl}$ impurity is not included.

- Allow more finely-defined constraints on waste management. For example, addressing the Mo constraint on glass independent of Ru-Rh-Pd would require either an approximate constant split of Mo-Ru-Rh-Pd into these two components or adjusting VISION to track these two glassconstraining masses separately.

For these reasons, the complementary FIT model tracks 287 items and no two elements are grouped together. We see no reason to expand VISION's complexity to such a degree.

\subsubsection{Fuel composition adjustment}

Before a single line of code was written for VISION, we considered the fact that the fuel composition in recycle scenarios is never constant with time. There are always variations in the isotope and/or chemical composition of fuel material because of the material coming from different reactors, different burnups, different aging times, and indeed different locations within reactors. So, a three part strategy was envisioned.

1. Provide a wide range of available fuel input and output recipes. Implemented.

2. For selective situations, provide a correlation that allows a smoothly varying recipe as a function of a key variable such as LWR fuel burnup. Implemented for LWR fuel burnup and it would be straightforward to finish implementation of FR-metal and FR-oxide correlations as function of $\mathrm{CR}$ from 0.0 to 1.0 , or even to extend the existing correlations to $\mathrm{CR}=1.75$.

3. Provide a built-in fuel composition adjustment. This has been implemented in FIT but not VISION.

We did not envision using a fourth option of calling a reactor physics depletion model to adjust compositions, to keep the model running in a matter of minutes on PCs.

Note that a composition adjustment approach must adjust both input and output, as conceptualized in Figure 2-3. The problem starts with multiple and varying potential sources of fuel material. In theory, when managing a real fuel cycle, one might use various control knobs such as different aging and sequencing of use of the potential feed streams - to either keep the material flowing into separations as constant as possible or to deliberately vary it for some purpose. VISION simply puts all the material designated for a particular reactor and fuel type in a single buffer. 


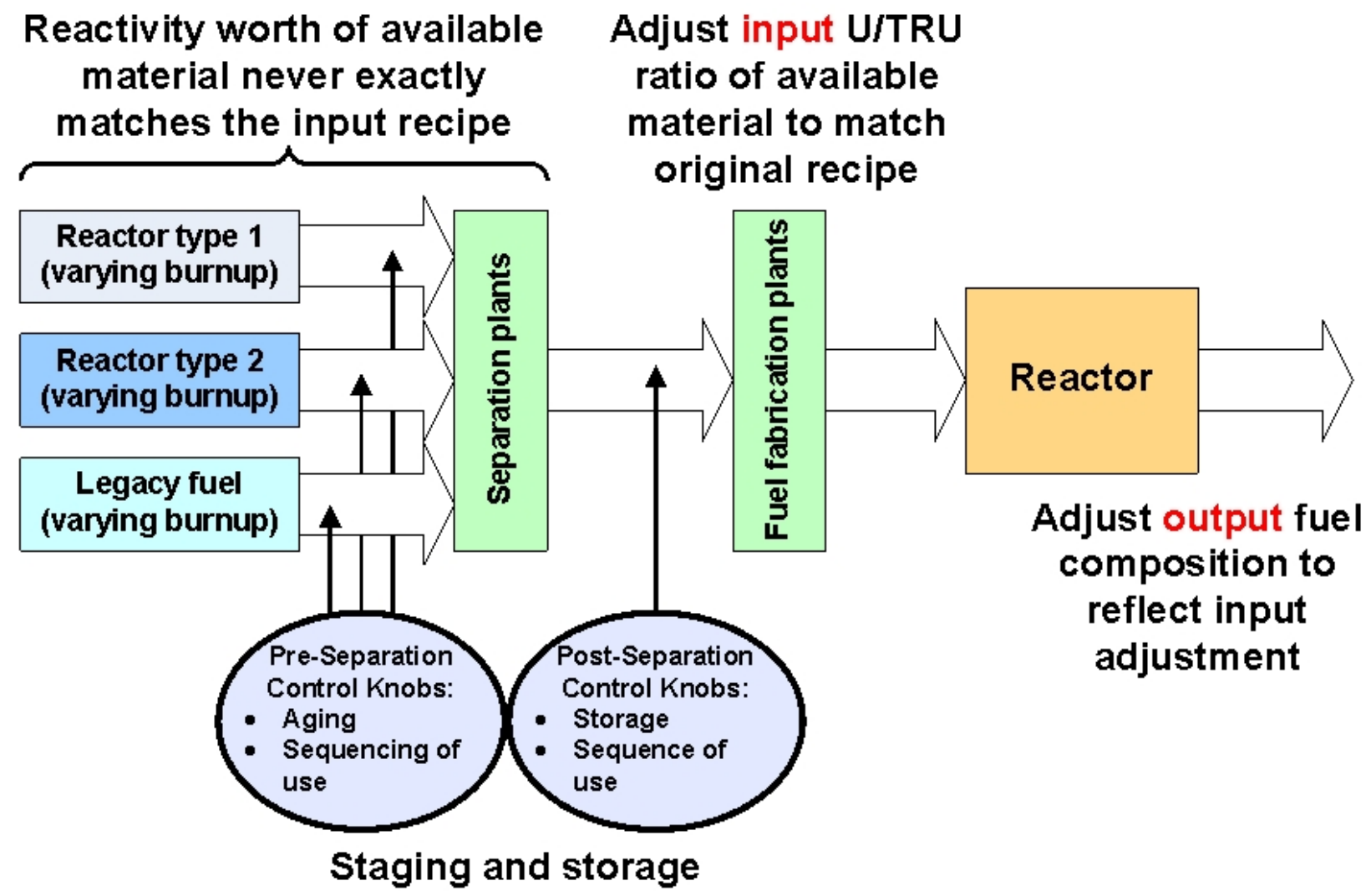

Figure 2-3. Fuel composition adjustment schemes.

After separation, there are other hypothetical control knobs such as storage and sequence of use. VISION keeps all the material together.

In fuel fabrication, the current model uses the user-specified fuel recipe and one of the "flow control" options noted earlier. This does not account for isotopic composition variation, e.g., the Pu239/Pu241 ratio changing from what it is in the fixed recipe. The FIT model has an input adjustment scheme in which the 1-group cross sections are used to compare the available fuel material worth to that assumed in the selected fuel recipe. The $U$ to TRU ratio is adjusted accordingly. For example, if Pu241 has decayed more than in the selected recipe, the $U$ to TRU ratio is dropped to compensate. This 1-group adjustment approach could be implemented in VISION, or a depletion model could be called iteratively to find the "best" fuel composition based on the available materials and what chemical adjustments (such as U vs. TRU) are possible. The depletion model approach would be more accurate but more complex and time consuming during execution.

The final adjustment is the output, which must be changed in accordance to however the input has been changed. The FIT approach is to use a simple depletion model, MrTau. Simpler 1-group approaches were tried and rejected.

\subsubsection{Externally Driven Fuel or Waste Management}

Table 2-1 noted that the option of (time-dependent) external supply of HEU (for downblending), U233, or TRU is not included. Such supplies could be stockpiles from weapon dismantlement or an externallydriven source such as fission-fusion hybrids used for fuel breeding. Adding the simple stockpile or transfer of fuel option would be difficult (because of the look ahead algorithm for calculating fuel availability) but would not address any constraints if the source were fission-fusion hybrids or accelerator systems. That would require another model change. 
Similarly, if one wanted to account for externally-driven (accelerator, fission-fusion hybrid) transmutation of waste, that would have to be a model change.

\subsection{Will Eventually Need Economics}

Table 2-4 shows different conceptual levels of economic analyses. The current version of VISION has no economic capabilities. VISION 2 had VISION.ECON, which in the Table is denoted as part way between static equilibrium and cash flows. Eventually, the FCT program (or its successors) will need at least a cash flow treatment and possibly economic feedbacks.

Table 2-4. Hypothetical Categories of Economic Analyses.

\begin{tabular}{|c|c|c|c|}
\hline Type or level of analysis & Objectives & Example tools & Types of data required \\
\hline Static equilibrium & $\begin{array}{l}\text { Cost comparison of } \\
\text { options at static } \\
\text { equilibrium }\end{array}$ & G4.ECON & $\begin{array}{l}\text { Cost database, e.g., } \$ / k g- \\
\text { separated }\end{array}$ \\
\hline Cash flows & $\begin{array}{l}\text { Cost comparison of } \\
\text { options, including time } \\
\text { value of money }\end{array}$ & $\begin{array}{l}\text { None yet } \\
\text { Note that this } \\
\text { requires } \\
\text { modeling all } \\
\text { non-commodity } \\
\text { costs as \# of } \\
\text { facilities. } \\
\text { VISION is close } \\
\text { to doing this. }\end{array}$ & $\begin{array}{l}\text { - For all non-commodity } \\
\text { costs, (a) divide } \$ / \mathrm{kg} \text { into } \\
\text { capital cost }+ \text { operating cost } \\
\text { and (b) spread out capital } \\
\text { cost during years of } \\
\text { construction. } \\
\text { - Determine how to assess } \\
\text { asset/liability of used fuel } \\
\text { and separated actinides. } \\
\text { - Consider how to incorporate } \\
\text { time value of money. } \\
\text { - Uranium cost as function of } \\
\text { amount used, rate of use, \& } \\
\text { rate of increase of use (i.e. } \\
\text { market effects) }\end{array}$ \\
\hline Economic feedbacks & $\begin{array}{l}\text { Incorporate economics } \\
\text { into time-dependent } \\
\text { scenarios to obtain more } \\
\text { realistic scenarios }\end{array}$ & None yet & $\begin{array}{l}\text { - Algorithms for deciding } \\
\text { which type of reactor to } \\
\text { build as function of cost. } \\
\text { - Others as appropriate. }\end{array}$ \\
\hline
\end{tabular}

\subsection{Validation and Verification}

Validation and verification has been addressed in the following ways:

- Review by internal INL summer interns.

- Review by SNL experts in software V\&V.

- Internal comparison of benchmark calculations.

- National and international benchmark exercises.

- Cross checking of results, such as with dynamic equilibrium calculations in Chapter 1.

But, V\&V is never a completed function. Many of the functions and capabilities in VISION have no peer to benchmark against. We welcome suggestions for further $\mathrm{V} \& \mathrm{~V}$. 


\subsection{What Else?}

Six years of experience with VISION has taught us that despite our best attempts, we cannot anticipate all future needs of the program. It is easy to say - make the model flexible - but this is not an "absolute". The current model is very flexible in some ways but constrained in others.

Some potential needs are as follows:

- A University of Wisconsin student, Tracy Radel, made a performance-related VISION sub-model that estimated (using ANL calculations) the heat impact of different waste streams on a Yucca Mountain-type geologic repository. Re-adding that to the current VISION model would not be a change to the fuel cycle capabilities but would enable a new performance output.

- Uranium recovered from separations (RU) can be re-enriched using the isotope-specific separation factors, but the associated amount of separative work units (SWUs) would not be tracked by the model. A relatively simple model change would enable that.

- FR-oxide and FR-metal correlations from $\mathrm{CR}=0.00$ to $\mathrm{CR}=1.00$ or (even better) to $\mathrm{CR}=1.75$. 


\section{DATA}

In this report, "data" means experimental data, data from more detailed theoretical or empirical calculations on technology performance, and assumptions such as the earliest date a technology can be deployed. This chapter is divided as follows: front end, fuel fabrication, reactors, separations, waste management, and the fuel cycle as a whole

\subsection{Front End}

Table 3-1 shows data status for the front end. At present, these VISION modules are all modeled as commodities. Data are adequate except in two circumstances: (a) economic feedbacks such as calculation of optimum DU tails or whether to re-enrich uranium and (b) if the need arose to model one or more parts of the front end as facilities instead of commodities.

Table 3-1. Status of Front End Data.

\begin{tabular}{|c|c|c|}
\hline & If modeled as commodities & $\begin{array}{l}\text { Additional information needed if } \\
\text { modeled as facilities }\end{array}$ \\
\hline $\begin{array}{l}\text { Portions of fuel } \\
\text { cycle in current } \\
\text { model }\end{array}$ & $\begin{array}{l}\text { - Uranium ore } \\
\text { - Uranium conversion } \\
\text { - Uranium separation }\end{array}$ & \\
\hline Data we have & $\begin{array}{l}\text { - Estimates of available uranium ore } \\
\text { - Equation for calculating SWUs } \\
\text { based on the composition of fuel, } \\
\text { product, and tails. } \\
\text { - Estimate of time material spends in } \\
\text { enrichment ( } 1 \text { year) } \\
\text { - Reasonable guesses for the } \\
\text { composition of DU (either } 0.20 \text { or } \\
0.25 \% \text { U235) } \\
\text { - Cost of the above in } \$ / \mathrm{kg} \text {. }\end{array}$ & \\
\hline $\begin{array}{l}\text { Data we do not } \\
\text { have }\end{array}$ & $\begin{array}{l}\text { If economics were added to VISION, } \\
\text { - A model that estimated the } \\
\text { optimum DU tails. } \\
\text { - Uranium re-enrichment costs as } \\
\text { function of relevant parameters } \\
\text { - Uranium cost as function of } \\
\text { uranium use, time lags for new } \\
\text { mines, etc. }\end{array}$ & $\begin{array}{l}\text { - When new technologies first available, } \\
\text { e.g., laser enrichment } \\
\text { - Technology deployment constraints } \\
\text { - Time lags for construction and } \\
\text { licensing } \\
\text { - Capacity factor } \\
\text { - Unit size } \\
\text { - Receipt rate into facilities } \\
\text { - Facility lifetime } \\
\text { - Capital costs } \\
\text { - Operating and maintenance costs }\end{array}$ \\
\hline
\end{tabular}

\subsection{Fuel Fabrication}

Table 3-2 shows data status for fuel fabrication. One particular item deserves attention - we know little about waste streams and waste forms from fuel fabrication. As there is increased attention to waste estimates of all classifications, the fabrication contribution to waste needs exploration. 
Table 3-2. Status of Fuel Fabrication Data.

\begin{tabular}{|c|c|c|c|}
\hline & Oxide fuels & Metal fuels & All other fuels \\
\hline $\begin{array}{l}\text { Reasonable } \\
\text { guesses exist, } \\
\text { e.g., in } \\
\text { DSARR } \\
\text { assumptions }\end{array}$ & $\begin{array}{l}\text { - When technology first } \\
\text { available } \\
\text { - Technology } \\
\text { deployment constraints } \\
\text { - Estimate for time } \\
\text { material spends in fuel } \\
\text { fabrication (0.5 year) } \\
\text { - Time lags for } \\
\text { construction and } \\
\text { licensing } \\
\text { - Facility capacity factor } \\
\text { - Facility lifetime }\end{array}$ & $\begin{array}{l}\text { - When technology first } \\
\text { available } \\
\text { - Technology deployment } \\
\text { constraints } \\
\text { - Estimate for time } \\
\text { material spends in fuel } \\
\text { fabrication (0.5 year) } \\
\text { - Time lags for } \\
\text { construction and } \\
\text { licensing } \\
\text { - Facility capacity factor } \\
\text { - Facility lifetime }\end{array}$ & $\begin{array}{l}\text { - Estimate for time material } \\
\text { spends in fuel fabrication } \\
(0.5 \text { year })\end{array}$ \\
\hline $\begin{array}{l}\text { Data we do not } \\
\text { have }\end{array}$ & $\begin{array}{l}\text { - Waste forms from fuel } \\
\text { fabrication }\end{array}$ & $\begin{array}{l}\text { - Waste forms from fuel } \\
\text { fabrication }\end{array}$ & $\begin{array}{l}\text { - Waste forms from fuel } \\
\text { fabrication } \\
\text { - When technology first } \\
\text { available } \\
\text { - Technology deployment } \\
\text { constraints } \\
\text { - Time lags for construction } \\
\text { and licensing } \\
\text { - Facility capacity factor } \\
\text { - Facility lifetime } \\
\text { - Capital costs } \\
\text { - Operating and maintenance } \\
\text { costs }\end{array}$ \\
\hline
\end{tabular}

\subsection{Reactors}

Table 3-2 shows data status for fuel fabrication. One particular item deserves attention - we know little about minimum wet storage times. "Wet" means actively cooled, not necessarily water. There are two reasons the minimum wet storage times are important. First, as shown in Chapter 1, it is a key time lag in dynamic analyses. Second, following the Fukushima accident, it is reasonable to expect more attention to how much fuel for how long resides in relatively vulnerable wet storage versus dry storage casks. (This is not a new issue, but it will get more attention.)

In the DSARR study, we used minimum wet storage times as follows:

- 1-year for onsite separation and recycling

- $\quad 10$-year for offsite separation and recycling

Both were independent of fuel or heat generation rates. We now have a spreadsheet-based tool that allows estimation of any fuel's heat generation rate from $\sim 1$ hour after reactor discharge to $\sim 1 \mathrm{e} 9$ years given the isotopic composition at discharge.

The 1-year value is known to be conservative because fuel at INL EBR-II and Hanford has been recycled onsite with less cooling time. The 10-year value is conservative for LWR UOX as the French reportedly transport and separation used UOX (at $33 \mathrm{GWth}$-day/tonne-iHM burnup) in 3-5 years. But, examination of heat curves suggests that the 10-year value is overly optimistic for other, hotter fuels. 
Table 3-3. Status of Reactor Data.

\begin{tabular}{|c|c|c|c|}
\hline & LWRs & Traditional Fast Reactors & All other types of reactors \\
\hline $\begin{array}{l}\text { Reactor } \\
\text { physics data } \\
\text { we have }\end{array}$ & $\begin{array}{l}\text { - Fuel residence time as } \\
\text { function of burnup from } \\
33 \text { to } 100 \\
\text { - Input/output recipes }\end{array}$ & $\begin{array}{l}\text { - Fuel residence time as } \\
\text { function of TRU CR } \\
\text { (with fixed cladding } \\
\text { fluence) for } 0.00 \text { to } 1.75 \\
\text { for metal fuel, } 0.00 \text { to } \\
1.00 \text { for oxide fuel } \\
\text { - Input/output recipes }\end{array}$ & $\begin{array}{l}\text { - Reasonable input/output, } \\
\text { burnup, and fuel residence } \\
\text { time data for HWR with } \\
\text { NU and several recycle } \\
\text { fuels, for uranium-fueled } \\
\text { breed+burn FR. } \\
\text { - Limited residence time and } \\
\text { input/output data for } \\
\text { HTGR, MSR, handful of } \\
\text { Th/U233 cases. } \\
\text { - See Transmutation Library } \\
\text { [Piet2010a] }\end{array}$ \\
\hline $\begin{array}{l}\text { Reactor } \\
\text { technology } \\
\text { data we have }\end{array}$ & $\begin{array}{l}\text { - Thermal efficiency } \\
\text { - Capacity factor } \\
\text { - Unit size }\end{array}$ & $\begin{array}{l}\text { - Thermal efficiency } \\
\text { - Capacity factor } \\
\text { - Unit size }\end{array}$ & \\
\hline $\begin{array}{l}\text { Reasonable } \\
\text { guesses } \\
\text { exist, e.g., in } \\
\text { DSARR } \\
\text { assumptions }\end{array}$ & $\begin{array}{l}\text { - When technology first } \\
\text { available } \\
\text { - Technology deployment } \\
\text { constraints } \\
\text { - Time lags for construction } \\
\text { and licensing } \\
\text { - Reactor lifetime } \\
\text { - Minimum wet storage } \\
\text { time for UOX }\end{array}$ & $\begin{array}{l}\text { - When technology first } \\
\text { available } \\
\text { - Technology deployment } \\
\text { constraints } \\
\text { - Time lags for } \\
\text { construction and } \\
\text { licensing } \\
\text { - Reactor lifetime } \\
\text { - Minimum wet storage } \\
\text { time for onsite } \\
\text { separation of used fuel }\end{array}$ & \\
\hline $\begin{array}{l}\text { Data we do } \\
\text { not have }\end{array}$ & $\begin{array}{l}\text { - Defendable wet storage } \\
\text { times for any fuel besides } \\
\text { UOX. }\end{array}$ & $\begin{array}{l}\text { - Defendable wet storage } \\
\text { times in preparation for } \\
\text { offsite separation of used } \\
\text { fuel }\end{array}$ & $\begin{array}{l}\text { - No data for LWR targets } \\
\text { - No data for sustained } \\
\text { recycle of Th/U233 cases. } \\
\text { - No data for Th/U233 in FR. } \\
\text { - Thermal efficiency } \\
\text { - Capacity factor } \\
\text { - Unit size } \\
\text { - When technology first } \\
\text { available } \\
\text { - Technology deployment } \\
\text { constraints } \\
\text { - Time lags for construction } \\
\text { and licensing } \\
\text { - Reactor lifetime } \\
\text { - Minimum wet storage time } \\
\text { - Capital costs } \\
\text { - Operating and maintenance } \\
\text { costs }\end{array}$ \\
\hline
\end{tabular}


First, consider the impact of LWR UOX burnup on heat in Figure 3-1. The heat in the relevant time period is a strong function of LWR UOX burnup and so there is no a priori reason to assume that the minimum wet storage time for UOX-50 or UOX-100 is the same as UOX-33. For example, the heat from $\mathrm{UOX}-33$ at 5 years matches the heat from UOX-50 at 10 years.

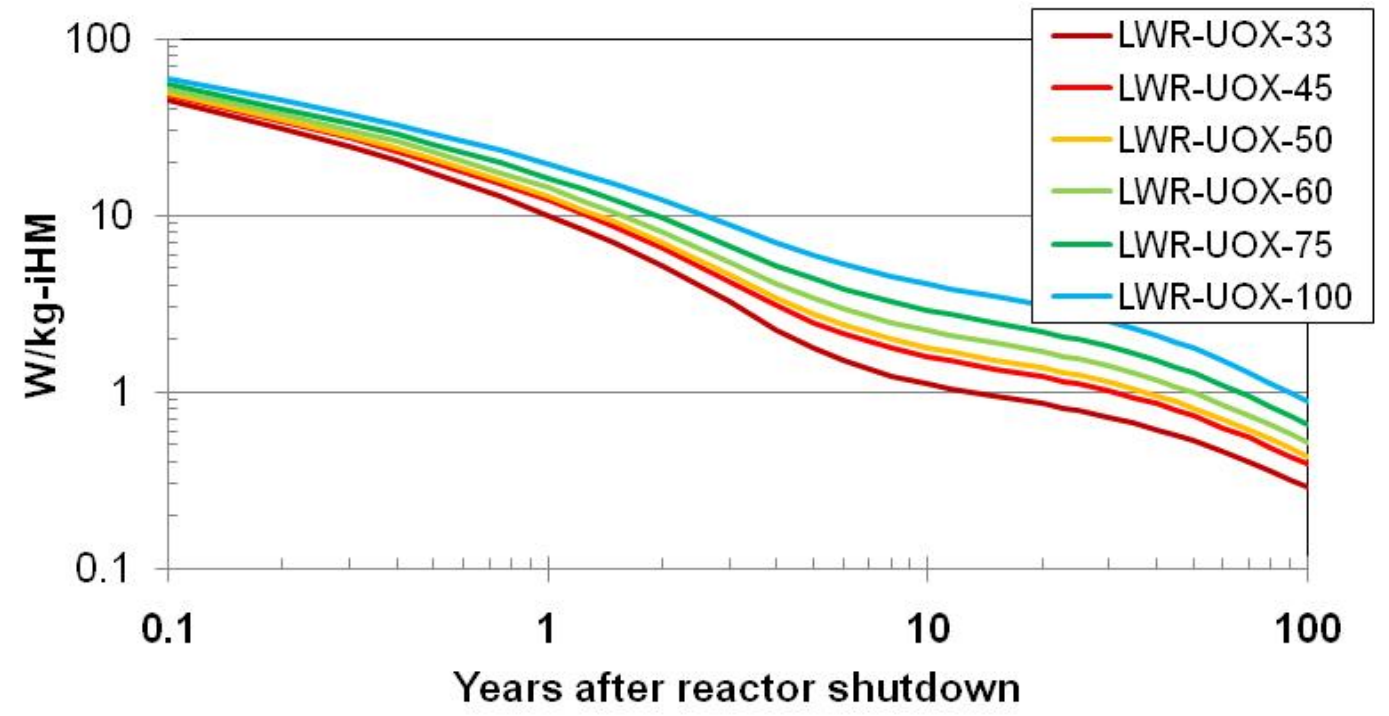

Figure 3-1. Heat generation rate of used fuel as function of LWR UOX burnup.

In this time and heat regime, actinides dominate heat. So, it is unsurprising that the heat for recycle fuels (8-10\% actinides in MOX, 100\% actinides in IMF, 20-30\% actinides in fast reactor fuel) is higher than for LWR UOX. When comparing fuels, it is not obvious what unit of measure to use. For example, on a W/kg-iHM basis, LWR IMF is almost two orders of magnitude higher than LWR UOX, but there is far less heavy metal in a given fuel assembly. So, for illustration purposes here, we only compare LWR fuels (avoiding LWR vs. FR fuel assembly geometry questions) and use percent of operating power. If the same technology and criteria are applied to MOX and IMF as UOX, it would seem that $\sim$ decade wet storage for UOX would need to be several decades for MOX or IMF. This requires more analysis and estimation of minimum wet storage times for the range of candidate fuels.

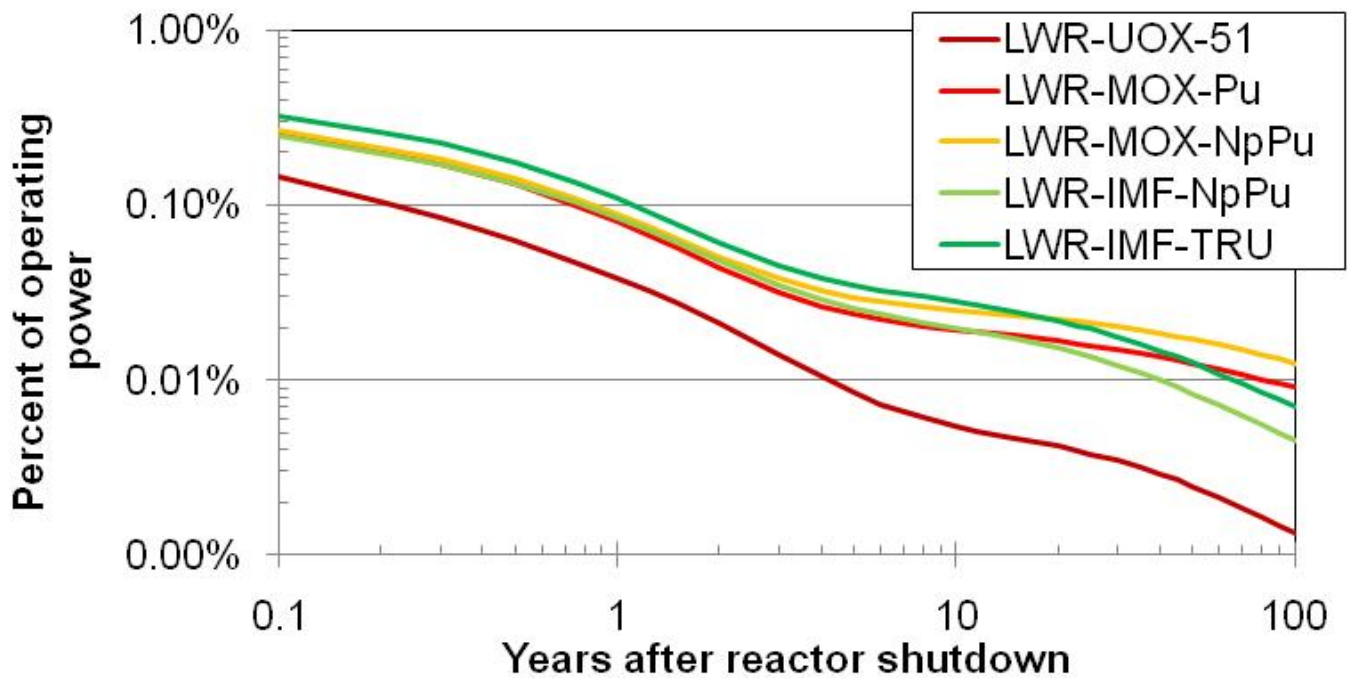

Figure 3-2. Heat generation rate of used fuel as function of LWR fuel. 
Table 3-3 also summarizes the status of minimum reactor physics data. To do a good dynamic analysis with VISION, one needs the following physics data:

- Burnup, GWth-day/tonne-iHM

- Fuel residence time, in years

- Input and output composition, by isotope, and by recycle pass (if a recycle case)

Of course, without those data, no quantitative analysis is possible - dynamic or static.

The LWR portion of the Transmutation Library is reasonably complete for U/Pu239 options, except for "targets" for which there is no data.

The Th/U233 data base is quite limited, with one recycle data in LWR and partial data for the MSR, but the latter assumes total salt direct disposal after 3 or 15 years. Neither is for a sustainable recycle case.

\subsection{Separations}

Table 3-4 summarizes the status of separations data. There is reasonable data for aqueous and electrochemical options, except that it is mostly for existing options that may or may not be appropriate for truly advanced fuel cycles. 
Table 3-4. Status of Separations Data.

\begin{tabular}{|c|c|c|c|}
\hline & Aqueous & Electrochemical & All other types of separations \\
\hline $\begin{array}{l}\text { Reasonable } \\
\text { guesses exist, } \\
\text { e.g., in } \\
\text { DSARR } \\
\text { assumptions }\end{array}$ & $\begin{array}{l}\text { - Candidate separation } \\
\text { strategies (what } \\
\text { elements are grouped } \\
\text { together) } \\
\text { - Separation efficiencies } \\
\text { - Waste form candidates } \\
\text { with current and near- } \\
\text { term technologies } \\
\text { - When technology first } \\
\text { available } \\
\text { - Technology deployment } \\
\text { constraints } \\
\text { - Time lags for } \\
\text { construction and } \\
\text { licensing } \\
\text { - Facility capacity factor } \\
\text { - Facility lifetime }\end{array}$ & $\begin{array}{l}\text { - Candidate separation } \\
\text { strategies (what } \\
\text { elements are grouped } \\
\text { together) } \\
\text { - Separation efficiencies } \\
\text { - Waste form candidates } \\
\text { with current and near- } \\
\text { term technologies } \\
\text { - When technology first } \\
\text { available } \\
\text { - Technology } \\
\text { deployment constraints } \\
\text { - Time lags for } \\
\text { construction and } \\
\text { licensing } \\
\text { - Facility capacity factor } \\
\text { - Facility lifetime }\end{array}$ & \\
\hline $\begin{array}{l}\text { Data we do not } \\
\text { have }\end{array}$ & $\begin{array}{l}\text { - Waste form candidates } \\
\text { with advanced } \\
\text { technologies } \\
\text { - Capital costs } \\
\text { - Operating and } \\
\text { maintenance costs }\end{array}$ & $\begin{array}{l}\text { - Waste form candidates } \\
\text { with advanced } \\
\text { technologies } \\
\text { - Capital costs } \\
\text { - Operating and } \\
\text { maintenance costs }\end{array}$ & $\begin{array}{l}\text { - Candidate separation } \\
\text { strategies (what elements } \\
\text { are grouped together) } \\
\text { - Separation efficiencies } \\
\text { - Waste form candidates } \\
\text { - When technology first } \\
\text { available } \\
\text { - Technology deployment } \\
\text { constraints } \\
\text { - Time lags for construction } \\
\text { and licensing } \\
\text { - Facility capacity factor } \\
\text { - Facility lifetime } \\
\text { - Capital costs } \\
\text { - Operating and maintenance } \\
\text { costs }\end{array}$ \\
\hline
\end{tabular}

\subsection{Waste Management}

The preceding subsections contain the issues associated with direct waste stream production and selection of which waste forms from fabrication and fuel separation. This subsection addresses the facilities and constraints in actually making the wasteform and then disposing of them. See Table 3-5. 
Table 3-5. Status of Waste Management Data.

\begin{tabular}{|c|c|c|}
\hline & If modeled as commodities & $\begin{array}{l}\text { Additional information needed if } \\
\text { modeled as discrete facilities }\end{array}$ \\
\hline $\begin{array}{l}\text { Portions of fuel } \\
\text { cycle }\end{array}$ & $\begin{array}{l}\text { Examples } \\
\text { - Co-flow of Zr, C, steel } \\
\text { - Waste packaging } \\
\text { - LLW-A/B/C storage } \\
\text { - LLW-GTCC storage } \\
\text { - Decay storage } \\
\text { - TRU waste }\end{array}$ & $\begin{array}{l}\text { Examples } \\
\text { - Repository } \\
\text { - MRS }\end{array}$ \\
\hline Data we have & $\begin{array}{l}\text { For aqueous and electrochemical } \\
\text { there are currently used data for ... } \\
\text { - Wasteform mass per waste (waste } \\
\text { loading) } \\
\text { - Wasteform volume per wasteform } \\
\text { mass (wasteform density) }\end{array}$ & $\begin{array}{l}\text { For Yucca Moutain, we have reasonable } \\
\text { estimates for needed data. }\end{array}$ \\
\hline $\begin{array}{l}\text { Data we do not } \\
\text { have }\end{array}$ & $\begin{array}{l}\text { - Data for co-flows } \\
\text { - Criteria for differentiating among } \\
\text { LLW-A/B/C (low heat, low } \\
\text { duration), LLW-GTCC (low heat, } \\
\text { high duration), decay storage waste } \\
\text { (high heat, low duration), and } \\
\text { HLW (high heat, high duration) - } \\
\text { using only current regulations for } \\
\text { advanced fuel cycles is a } \\
\text { questionable approach. } \\
\text { - Waste stream and waste form } \\
\text { properties for separations and fuel } \\
\text { fabrication processes that have not } \\
\text { been already used at a relatively } \\
\text { large industrial scale. }\end{array}$ & $\begin{array}{l}\text { For options other than Yucca Mountain, } \\
\text { - When technology first available } \\
\text { - Technology deployment constraints } \\
\text { - Time lags for construction and } \\
\text { licensing } \\
\text { - Inventory limit per storage/disposal } \\
\text { facility } \\
\text { - Facility lifetime } \\
\text { - Repository and MRS receipt rate } \\
\text { and/or inventory limit by year } \\
\text { - Capital costs } \\
\text { - Operating and maintenance costs }\end{array}$ \\
\hline
\end{tabular}

The most immediate data needs are probably associated with waste management for anything other than current technology. For example, we know little about waste forms for waste streams arising from fuel fabrication when the fuel feedstocks contain actinides from recycled fuel (and trace amounts of fission products that may not be perfectly separated from the fuel actinides).

Where we do have data, often it is of fairly old technologies, hardly appropriate for judging advanced fuel cycles to be deployed decades from now. Estimates of waste generation based on DOE separations facilities from decades ago risks being conservatively high for two reasons. First, the old technologies may not fairly represent technologies and processes in future fuel cycles. Second, decades-old DOE separations processes were operated with different drivers and constraints compared to potential future, larger-scale processes, in which process efficiencies and waste minimization may be valued more highly. Process efficiencies and waste minimization in future processes may be both more feasible and incentivized by regulations or economics than they were in historical processes.

Research and development continues in separations, fuel fabrication, and waste treatment and wasteform technologies. In many cases, the more that is learned about a separations or fabrication process, the more we realize the waste management issues that need to be addressed. For example, used fuel separations based on different volatilities or solubilities of oxidized, halogenated, sulfated, or nitrated species has 
been studied as early as 60 years ago. Interest in separation processes not yet used in recent history has been renewed, in efforts to avoid some of the perceived disadvantages of the currently used or more fully developed aqueous solvent extraction processes. But as study of these processes is renewed, we learn more about not only the perceived advantages but also disadvantages of new types of processes. A recent study has reviewed five different innovative separations technologies, that are mostly derivatives of the decades-old fluoride volatility separations processes, and has identified considerable uncertainty in the potential characteristics of waste streams and waste forms from such advanced processes, and uncertainty in (and potential for minimizing) the amounts of those waste forms.[Tripp2011]

We expect that, considering the existing reference-able recent reports from studies that have estimated waste generation in used from fuel processing, we can make reasonable order-of-magnitude guesses for waste management from aqueous separations that have been demonstrated or used at large or commercial scales. In addition, we can make reasonable guesses at waste management for electrochemical reprocessing, considering the years of relatively smaller-scale but industrialized electrochemical separations. Guesswork increases for other, less developed separations processes, including many variations on aqueous and electrochemical separations and other innovative separations processes, and for fuel fabrication using recycled actinides from used fuel.

\subsection{Data for Fuel Cycles}

The preceding sections are focused on individual technologies. A fuel cycle, however, is more than the sum of parts. This is typically realized when one assemblies a simulation in either VISION or FIT. Some of the additional things that must be specified beyond individual technologies are as follows:

- Are there any modifications of technology-specific time lags when combined in the way being analyzed, e.g., if LWR UOX normally must wait X years in wet storage before going to a separation plant, is the same value appropriate if the fuel is to go to an electrochemical plant? Essentially every one of the preceding time lag data must be re-checked for a particular fuel cycle scenario.

- Are there any modifications of technology-specific composition data when combined in the way being analyzed, e.g., it is acceptable to keep all the uranium with recovered TRU when electrochemical is used on fast reactor fuel to make new fast reactor fuel. But, if making LWR MOX ( $8-10 \%$ TRU) from used LWR UOX ( $1 \%$ TRU), most of the uranium must be separated from the LWR UOX TRU. So, a FR-to-FR separation specification may have to be altered for a UOX-to-MOX scenario.

- How are the different sources of used fuel to be "pulled" into separation plants, with what priority?

- How are different possible separation products to be "pushed" into fuel fabrication?

- How quickly can technology performance be changed? For example, VISION allows one to change separation plant separation matrix and reactor fuel type each year. That is fine if the change is minor, say from LWR UOX burnup $\mathrm{X}$ to $\mathrm{X}+1$. But, are more dramatic changes realistic.

- It is obvious that dynamic analyses require knowing when a new technology is first available. What is sometimes less obvious is whether there are to be constraints on the subsequent deployment of that technology. Limited facility capacity? Limited capacity factor? If so, VISION has various ways to implement such constraints. 


\section{CONCLUSIONS}

Table 4-1 shows possible tool development needs. The most immediate tool need is extending VISION to the thorium/U233 fuel cycle. Depending on further clarification of waste management strategies in general and for specific fuel cycle candidates, waste management sub-models in VISION may need enhancement, e.g., more on "co-flows" of non-fuel materials, constraints in waste streams, or automatic classification of waste streams on the basis of user-specified rules. VISION originally had an economic sub-model. The economic calculations were deemed unnecessary in later versions so it was retired. Eventually, the program will need to restore and improve the economics sub-model of VISION to at least the cash flow stage and possibly to incorporating cost constraints and feedbacks.

Table 4-1. Possible Tool Development Needs.

\begin{tabular}{|c|c|c|}
\hline & & Why \\
\hline Thorium/U233 & Need & $\begin{array}{l}\text { Largest single barrier to covering } \\
\text { the option space from the initial } \\
\text { FCT screening activity }\end{array}$ \\
\hline Waste management/ co-flows & Need & $\begin{array}{l}\text { Assessment of waste are simply } \\
\text { inaccurate without accounting for } \\
\text { non-fuel materials (cladding, } \\
\text { coating, fuel assembly structure, } \\
\text { etc.) }\end{array}$ \\
\hline Waste management/ constraint-driven & Likely need & $\begin{array}{l}\text { Would increase credibility of } \\
\text { estimates. }\end{array}$ \\
\hline Waste management/ automatic waste classification & May need & $\begin{array}{l}\text { Allows testing of different } \\
\text { hypothetical criteria, but should } \\
\text { be developed and tested in FIT } \\
\text { first. }\end{array}$ \\
\hline Routing/ targets & \multirow[t]{3}{*}{ May need } & \multirow{3}{*}{$\begin{array}{l}\text { Depends on FCT program } \\
\text { directions and priorities. }\end{array}$} \\
\hline Routing/push and pull & & \\
\hline Routing/ priorities & & \\
\hline Physics/more isotopes & May need & $\begin{array}{l}\text { Only if waste assessments } \\
\text { require. }\end{array}$ \\
\hline Physics/ fuel adjustment & Likely need & $\begin{array}{l}\text { Would increase credibility of } \\
\text { estimates. }\end{array}$ \\
\hline Physics/ externally driven systems & Unlikely & $\begin{array}{l}\text { Externally-driven systems can } \\
\text { either provide fuel or waste } \\
\text { transformation services, but } \\
\text { practicality is questionable and } \\
\text { those questions need to be } \\
\text { addressed before considering } \\
\text { VISION calculations. }\end{array}$ \\
\hline Economics/ \$/kg & \multirow{3}{*}{$\begin{array}{l}\text { Not "if" but } \\
\text { "when" }\end{array}$} & \\
\hline Economics/ cash flows & & \\
\hline Economics/ feedbacks & & \\
\hline
\end{tabular}

In this report, "data" means experimental data, data from more detailed theoretical or empirical calculations on technology performance, and assumptions such as the earliest date a technology can be deployed.

The most immediate data needs are probably associated with waste management for anything other than current technology. 
- We lack a defendable basis for minimum wet storage times for most candidate fuels other than (a) LWR UOX or (b) onsite separation of fast reactor metal fuel, e.g. at EBR-II.

- We know little about waste forms for waste streams arising from fuel fabrication. Where we do have data, often it is of fairly old technologies, hardly appropriate for judging advanced fuel cycles to be deployed decades from now.

- Criteria for differentiating among LLW-A/B/C (low heat, low duration), LLW-GTCC (low heat, high duration), decay storage waste (high heat, low duration), and HLW (high heat, high duration) - using only current regulations for advanced fuel cycles is a questionable approach.

- Approaches for disposal options other than Yucca Mountain need to be hypothesized.

To do quantitative analysis, one needs the following physics data:

- Burnup, GWth-day/tonne-iHM

- Fuel residence time, in years

- Input and output composition, by isotope, and by recycle pass (if a recycle case)

Of course, without those data, no quantitative analysis is possible-dynamic or static. The LWR portion of the Transmutation Library is reasonably complete for U/Pu239 options, except for "targets" for which there is no data. The Th/U233 data base is quite limited, with one data available for a single recycle in LWR and partial data for the MSR, but the latter assumes total salt direct disposal after 3 or 15 years. Neither is for a sustainable recycle case.

To do quantitative analysis, one needs the separation data. For each major group of chemical elements, where do they go? Feedstock for new fuel? Waste? We have reasonable data for several aqueous separation options and electrochemical. Beyond that, no.

If future FCT needs requiring changing the modeling approach from "commodity" to "facility", then data will have to be assembled associated with facility versions of the function in question, including as follows:

- When new technologies first available, e.g., laser enrichment

- Technology deployment constraints

- Time lags for construction and licensing

- Capacity factor

- Unit size

- Receipt rate into facilities

- Facility lifetime

When economics is restored in dynamic analyses tools, we will need estimates of both capital cost and operating and maintenance costs.

The readiness of tools and data is fluid and depends on what purposes are envisioned to drive upcoming analyses and further definition of the waste-related characteristics of fuel cycle candidates. Tools and data sets evolve as needs evolve. Thus, much of the document explains that if the FCT program wants a certain type of analysis, then the tools and data needs are as indicated. For example, functions can be treated as either commodities or facilities. Reactors, separation, fuel fabrication, repository are treated as facility types. Other functions such as uranium mining, conversion, enrichment, and waste packaging and non-repository disposal are treated as commodities. For example, if the FCT program wants to explore the implications of time lags in opening new uranium mines or enrichment plants, then the VISION's uranium sub-models would have to be converted from commodity to facility. In summary, the tools are functional and can answer many fuel cycle questions but some analyses will require that the tools be modified to support those analyses 


\section{REFERENCES}

Bays2009 S. Bays, S. Piet, M. Pope, G. Youinou, A. Dumontier, D. Hawn, "Transmutation Dynamics: Impacts of Multi-Recycling on Fuel Cycle Performances," AFCI-SYSAPMO-MI-DV-2009-000185, INL/EXT-09-16857, September 2009.

Bays2010 S. E. Bays, S. J. Piet, N. R. Soelberg, M. Lineberry, and B. W. Dixon, "Technology Insights and Perspectives for Nuclear Fuel Cycle Concepts," FCRD-SYSA-2010-000184, INL/EXT-10-19977, September 30, 2010.

Carter2011 J. T. Carter, A. J. Luptak, and J. Gastelum, "Fuel Cycle Potential Waste Inventory for Disposition," FCR\&D-USED-2010-000031, Revision 3, April 2011.

Dixon2008 Brent W. Dixon, William Halsey, Sonny Kim, Gretchen Matthern, Steven Piet, David Shropshire, "Dynamic Systems Analysis Report for Nuclear Fuel Recycle," Revision 1, AFCI-SYSA-AI-SS-RT-2009-000053, Advanced Fuel Cycle Initiative, December 2008.

Gombert2008 Dirk Gombert II, "Global Nuclear Energy Partnership Integrated Waste Management Strategy,” GNEP-WAST-WAST-AI-RT-2008-000214, May 2008.

Jacobson2005 Jake Jacobson, William West, David Shropshire, "Software Platform Evaluation Verifiable Fuel Cycle Simulation (VISION) Model, Rev 0., November 2005.

Jacobson2010 J. J. Jacobson, A. M. Yacout, G. E. Matthern, S. J. Piet, D. E. Shropshire, R. F. Jeffers, T. Schweitzer, "Verifiable Fuel Cycle Simulation Model (VISION): A Tool for Analyzing Nuclear Fuel Cycle Futures," Nuclear Technology, 172 (2), November 2010, pp. 157178.

Jacobson2011 Jacob J. Jacobson, Robert F. Jeffers, Gretchen E. Matthern, Steven J. Piet, Wendell D. Hintze, "User Guide for VISION 3.4 (Verifiable Fuel Cycle Simulation) Model, AFCISYSA-AI-MI-GD-2009-000152/Rev3, INL/EXT-09-16645/Rev 3, June 24, 2011.

Jones2011 R.H. Jones, "Low Level Waste Disposition - Quantity and Inventory," FCRD-USED2010-000033, Revision 2, June 2011.

ISEP2011 S. D. Sevougian, M. Gross, E. Hardin, E. Hoffman, R. MacKinnon, L. Price, W. Halsey, J. Buelt, J. Gehin, M. Mullen, T. Taiwo, M. Todosow, R. Wigeland, "Initial Screening of Fuel Cycle Options,” FCRD-SYSE-2011-000040, Rev. 0, March 11, 2011.

Hardin2010 E. L. Hardin, L. L. Price, "Fuel Cycle Catalog Description and System Options for Initial Screening,” FCRD-SYSE-2010-000203, October 19, 2010, draft B.

Hoffman 2006 E. Hoffman, W. Yang, R. Hill, "Preliminary Core Design Studies for the Advanced Burner Reactor over a Wide Range of Conversion Ratios," ANL-AFCI-177, 2006.

Hoffman2007 E. A. Hoffman, "Updated Design Studies for the Advanced Burner Reactor over a Wide Range of Conversion Ratios," ANL-AFCI-189, May 31, 2007.

Hoffman2009 E. A. Hoffman, "FY09 ANL AFCI Transmutation Studies," ANL-AFCI-271, August 31, 2009.

Piet2005 S. J. Piet, G. E. Matthern, J. J. Jacobson, C. T. Laws, D. E. Shropshire, A. M. Yacout, R. N. Hill, E. Schneider, J. D. Smith, "Planning and Design Basis for the Verifiable Fuel Cycle Simulation (VISION) Model, December 21, 2005.

Piet2009 S. J. Piet, Selection of Isotopes and Elements for Fuel Cycle Analysis, "Advances In Nuclear Fuel Management IV (ANFM IV),” April 12-15, 2009, INL/CON-08-15050. 
Piet2010a Steven J. Piet, Samuel E. Bays, Edward A. Hoffman, "Description of Transmutation Library for Fuel Cycle System Analyses," FCRD-SYSA-2010-000116, INL/EXT-1019545, August 4, 2010.

Piet2010b Steven J. Piet, Nick R. Soelberg, Samuel E. Bays, Robert S. Cherry, Denia Djokić, Candido Pereira, Layne F. Pincock, Eric L. Shaber, Melissa C. Teague, Gregory M. Teske, Kurt G. Vedros, "System Losses Study - FIT (Fuel-cycle Integration \& Tradeoffs), FCRD-SYSA-2010-000140, September 15, 2010.

Piet2011a S. J. Piet, B. W. Dixon, J. J. Jacobson, G. E. Matthern, D. E. Shropshire, "Lessons Learned from Dynamic Simulations of Advanced Fuel Cycles," Nuclear Technology, 173 (3), March 2011, pp. 227-238.

Piet2011b Steven J. Piet, Nick R. Soelberg, Layne F. Pincock, Eric L. Shaber, Gregory M. Teske, "The FIT 2.0 Model - Fuel-cycle Integration and Tradeoffs," FCR\&D-SYSA-2010000192, rev 1, INL/EXT-10-20190, rev 1, June 14, 2011.

Pope2009 M. Pope, S. Bays, S. Piet, R. Ferrer, M. Asgari, B. Forget, "Transmutation Performance Analysis for Inert Matrix Fuels in Light Water Reactors and Computational Neutronics Methods Capabilities at INL," INL/EXT-07-12472, Rev. 1, May 1, 2009.

Shropshire2005 AFCI Economic Benefits and Systems Analysis Team, "Software Requirements Specification - Verifiable Fuel Cycle Simulation (VISION) Model," INEEL/EXT-0502643, Rev. 1, November 2005.

Shropshire2009 D. E. Shropshire, K. A. Williams, J. D. Smith, B. W. Dixon, M. Dunzik-Gougar, R. D. Adams, D. Gombert, J. T. Carter, E. Schneider, D. Hebditch, “Advanced Fuel Cycle Cost Basis," INL/EXT-07-12107, December 2009.

Soelberg2010 N.R. Soelberg, et al, "Waste Stream Analyses for Nuclear Fuel Cycles," FCRD-SASA2010-000109, INL/EXT-10-19643, August 11, 2010.

Stillman2004 J. A. Stillman, "Homogeneous Recycling Strategies in LWRs for Plutonium, Neptunium, and Americium Management," Argonne National Laboratory, ANL-AFCI-124, August 2004.

Tripp2011 J. Tripp, N. Soelberg, and R. Wigeland, "Innovative Separations Technologies," FCR\&D-SYSA-2011-000097, INL/EXT-11-22297, May 31, 2011.

Wigeland2009 R. Wigeland, T. Taiwo, M. Todosow, W. Halsey, J. Gehin, “AFCI Options Study," AFCI-TIO-PMO-MI-DV-2009-000086, Advanced Fuel Cycle Initiative, September 2009.

Wigeland2010 R. Wigeland, T. Taiwo, M. Todosow, W. Halsey, J. Gehin, "Options Study - Phase II," FCRD-TIO-2010-000167, Fuel Cycle Research and Development Program, September 2010.

Yee2008 Shannon K. Yee, "Nuclear Fuel Cycle Modeling Approaches for Recycling and Transmutation of Spent Nuclear Fuel," Masters Thesis, Ohio State University, 2008.

Youinou2009 Gilles Youinou, Samuel Bays, "Homogeneous recycling of Pu or Pu+M.A. in PWRs loaded with MOX-UE fuel (MOX with U-235 enriched U support)," INL/EXT-09-16091, AFCI-SYSA-TRAN-SS-RT-2009-000055, June 2009. 